\title{
The Closed-Loop Supply Chain Network Equilibrium with Products Lifetime and Carbon Emission Constraints in Multiperiod Planning Horizon
}

\author{
Guitao Zhang, Hao Sun, Jinsong Hu, and Gengxin Dai \\ School of Management Science and Engineering, Qingdao University, Qingdao 266071, China \\ Correspondence should be addressed to Hao Sun; rivaldoking@gmail.com
}

Received 31 March 2014; Accepted 19 May 2014; Published 16 June 2014

Academic Editor: Xiaolin Xu

Copyright (C) 2014 Guitao Zhang et al. This is an open access article distributed under the Creative Commons Attribution License, which permits unrestricted use, distribution, and reproduction in any medium, provided the original work is properly cited.

\begin{abstract}
This paper studies a closed-loop supply chain network equilibrium problem in multiperiod planning horizons with consideration of product lifetime and carbon emission constraints. The closed-loop supply chain network consists of suppliers tier, manufacturer tier, retailers tier, and demand markets tier, in which the manufacturers collect used products from the demand markets directly. Product lifetime is introduced to denote the maximum times of manufacturing and remanufacturing, and the relation between adjacent periods is described by inventory transfer. By variational inequalities and complementary theory, the optimal behaviors of all the players are modeled, and, in turn, the governing closed-loop supply chain network equilibrium model is established. The model is solved by modified project contraction algorithm with fixed step. Optimal equilibrium results are computed and analyzed through numerical examples. The impacts of collection rate, remanufacturing conversion rate, product lifetime, and carbon emission cap on equilibrium states are analyzed. Finally, several managerial insights are given to provide decision support for entrepreneurs and government official along with some inspirations for future research.
\end{abstract}

\section{Introduction}

Closed-loop supply chain (CLSC) has received increasing attention coming from theorists and entrepreneurs in recent years. From the viewpoint of overall lifecycle, it compromises the forward activities of manufacturing, distribution, and retailing and backward activities of collection and remanufacturing. Remanufacturing, as the significant part of CLSC, is a complicated process in which the core components of used products are disassembled, repaired, and reused [1]. Compared with production from virgin materials, remanufacturing tends to be energy saving, less material consuming and often has a lower impact on the environment. Related studies have shown that the remanufacturing cost of a core component is typically $40-60 \%$ less than those of brand-new production by raw materials [2]. Many famous enterprises, such as Xerox, Robert Bosch Tool, Black and Decker, and Hewlett-Packard, have implemented remanufacturing and CLSC strategies successfully $[3,4]$.
In CLSC operations, the dynamic production, remanufacturing, and pricing strategies in multiperiod planning horizons are of great importance for the firms, which is directly related to their long-term profits. But for the decision-makers, it is much more complicated to make the optimal strategies in several planning horizons than in a single period, because they have to weigh the profit of the current period against those of the subsequent periods. One can easily deduce that if the price is high in the current period, the firm's profit in this period might increase whereas the quantity of the products sold decreases; in turn, in the subsequent periods, the number of remanufacturable products available decreases, therefore reducing the subsequent periods' potential profits. On the other hand, if the price is low in the current period, the profits in this period might decrease, but the manufacturers have more end-oflife products to remanufacture in future periods [5]. Then, in this context, how should the decision-makers make the best choice? Aiming at this issue, the scholars have done 
a lot of research from the viewpoint of a monopolistic manufacturer, duopoly manufacturers, and single manufacturersingle retailer/collector bilateral monopoly. Their research provides several meaningful management insights for the readers and the practitioners. However, as we know, the actual CLSC is likely to have a wider variety of channel members and complex cooperative and competitive relations. For example, a complete CLSC may have several mutual competitive suppliers, competitive manufacturers, competitive retailers, competitive collectors, and demand markets, in which each kind of players is sorted in the same tier, so the combination of any a player from each tier can form a cooperative chain. From another perspective, some players in the network such as a typical manufacturer or a typical retailer may be included in different CLSC. Therefore, the CLSC usually exists in the form of network structure. According to Hammond and Beullens [6], if and only if all the players in the CLSC network agree to the transaction prices and the transaction amounts of products, the equilibrium state of the CLSC network is achieved. Then, the following questions come up: for such a complex CLSC network, what are the players' optimal decisions in dynamic multiperiod planning horizons? What is the dynamic equilibrium state of the CLSC network?

In addition, the factors of product lifetime are usually neglected in the previous dynamic multiperiod CLSC modeling, and almost all of the literature assumed the used products could be remanufactured only once. But in reality, the core components may undergo multiple cycles of remanufacturing. For example, an end-of-life toner cartridge can be retreaded up to four times before landfill [7]. A singleuse camera can be remanufactured approximately 6 times [8]. Many others including the maximum lives of car rites and computer chips are 3 and 4, respectively [9]. Therefore, it is of great importance to take the factors of finite product lifetime into account in dynamic CLSC modeling.

Last but not least, as huge consumptions of fossil energies and accumulative carbon emissions of greenhouse gases have aggravated weather deterioration and environment pollution most recently, more and more attention on how to reduce carbon emissions has been received worldwide. Accordingly, a series of regulation policies are introduced by governments. Kyoto protocol is one of the most famous protocols signed at the third conference of the parties of United Nations Framework Convention on Climate Change held in Kyoto, Japan, in October, 1997. After Kyoto protocol, other policies, for example, EU-ETS, RGGI, are published subsequently [10]. Predictably, in the future the influence on enterprise operations will be more and more coming from carbon emission polices and gradually will be one of the prerequisites in the production/operations management for the firms. Therefore, for the players in CLSC network, how should they arrange their logistic activities when faced with the carbon emission policies?

Motivated by all the above analysis, this paper establishes a multiperiod CLSC network equilibrium model with consideration of product lifetime and carbon emission constraints comprehensively, analyzes the impact of a variety of parameters on CLSC network equilibrium, and obtains several managerial insights. We argue that this study is one of the first studies to explore CLSC network equilibrium in dynamic multiperiod planning horizons, not to mention that the other two important factors are considered simultaneously.

The rest of this paper is organized as follows. In Section 2, we review the literatures related to our research and highlight the contributions of our paper. In Section 3, we give the model assumptions and variable notations. In Section 4, we present our model in which the optimal behavior of various players in the multiperiod CLSC network is described and the governing equilibrium conditions are formulated as a finitedimension variational inequality problem. In Section 5, we provide a solving algorithm for the model. In addition, by a numerical example, we analyze the equilibrium results and reveal meaningful insights related to product lifetime and carbon emission constraints.

\section{Literature Review}

Our work is related to three streams of research, and the literature in each research will be reviewed subsequently. We will also point out how our study differs from the existing literature.

The first stream of research related to our work is on the dynamic production, pricing policies, and coordination mechanisms of CLSC in two-period, multiperiod, and infinite planning horizon settings [5, 11-18]. With the consideration of multiple product lifetimes, Geyer et al. [9] investigated the economy of remanufacturing and demonstrated the need to coordinate production cost structure, collection rate, constraints of limited component durability, and finite product life cycles in the process of production operations. Although the above-mentioned literatures lay a solid foundation for future research, they are confined merely to the case of a monopoly manufacturer, duopoly manufacturers, or single manufacturer-single retailer/collector bilateral monopoly. Our study differs from the above-mentioned literature in that we research into dynamic production and pricing decisions in a complex CLSC network.

The second stream of research related to our work is on network equilibrium of CLSC and multiperiod traditional/forward supply chain network equilibrium. Hammond and Beullens [6] construct an oligopolistic CLSC network model including manufacturers and demand markets under WEEE legislation. Yang et al. [19] use variational inequality method to model the CLSC network including suppliers, manufacturers who are involved in the production of a homogeneous product from virgin materials and collected materials, retailers, and recovery centers that collect used products from demand markets and can obtain subsidies from official organizations. Qiang et al. [20] establish a CLSC network model considering the competition, distribution channel investment, and uncertainties. The literature mentioned above deal with static or single-period CLSC network equilibrium problems.

Recently, a few authors explore multiperiod traditional supply chain network equilibrium problems. Cruz and Wakolbinger [21] develop a framework for the analysis of 
the optimal levels of corporate social responsibility (CSR) activities in a multiperiod supply chain network consisting of manufacturers, retailers, and consumers and describe the problem of carbon emissions. Hamdouch [22] establishes a three-tier equilibrium model with capacity constraints and retailers' purchase strategy from a multiperiod perspective. Cruz and Liu [23] analyze the effects of levels of social relationship on a multiperiod supply chain network with multiple decision-makers associated with different tiers. But to our knowledge, there is no research linking the dynamic multiperiod decisions and CLSC network equilibrium up to now. One intention of our work is to fill the gap.

The third stream of research related to our work is on the production planning with carbon cap schemes and carbon trade schemes. Emission cap scheme, as a traditional regulation, restricts the maximum carbon emission volumes of the firm at a certain time. In contrast, emissions trading schemes provide pollutant emitters with flexibility in how they comply with the regulations. It is not discussed in detail in this paper. We refer readers to the work Gong and Zhou [24] to reach a deeper understanding about production planning with carbon emission schemes. Herein, we will give a brief review on the literature that studies supply chain network equilibrium and CLSC supply chain operations problems with carbon emission constraints. Wu et al. [25] propose an electric power supply chain network equilibrium model with carbon taxes. Based on this model, Nagurney et al. [26] develop a modeling and computational framework that allowed for the determination of optimal carbon taxes applied to electric power plants in electric power supply chain networks. More recently, it has been incorporated into reverse logistics and CLSC modeling. Krikke [27] gives a decision framework for optimizing the combined disposition and location-transport decisions on carbon footprints in CLSC and then applies it to a copier case. Kannan et al. [28] establish a biobjective 0-1 mixed-integer linear programming model for a carbon footprint based reverse logistics network design. The difference between our study and the existing literature lies in that we combine the CLSC network equilibrium with carbon emission constraints.

\section{Model Assumptions and Notations}

3.1. Model Assumptions. Considering a CLSC network consisting of multiple suppliers, multiple manufacturers, multiple retailers, and multiple demand markets, in which the manufacturers make homogenous products and simultaneously collected used products from demand markets at the end of period $t$ for remanufacturing in the period $t+$ 1 , the criterion of each player in the network is its total profit maximum in multiperiod planning horizontal. The two-period CLSC network comprises two suppliers, two manufacturers, two retailers, and two demand markets which can be described as in Figure 1. We denote a typical raw material supplier by $s$, a typical manufacturer by $m$, a typical retailer market by $n$, and a typical demand market by $k$. In particular, $m_{1}(2)$ represents the 1st manufacturer in 2 nd period, and we can interpret the other notations in the

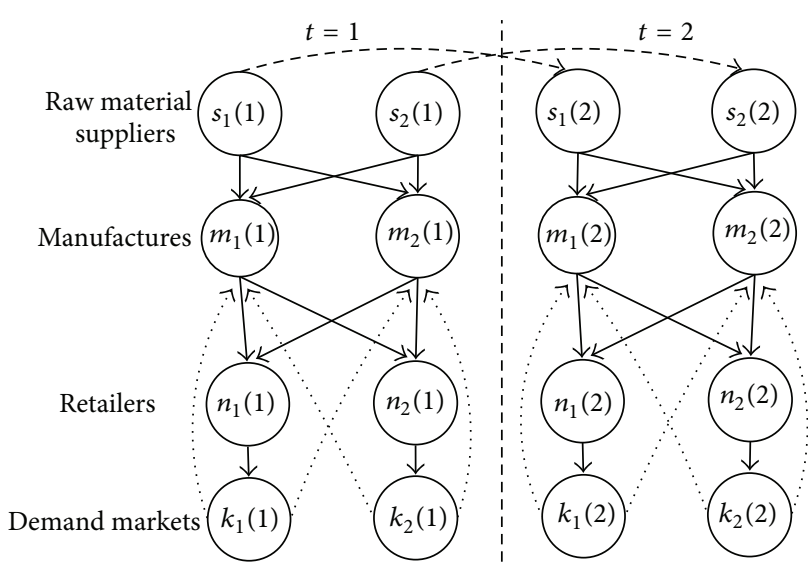

FIGURE 1: An illustration of a CLSC network with two periods.

same way. In the top of Figure 1, the dotted lines between the same manufacturers in different period represent the transfer of inventory between different planning periods. The real lines express the forward transactions between suppliers and manufacturers and manufacturers and retailers, and the thin dotted lines illustrate the reverse transactions between manufacturers and demand markets.

Due to the complexity of the problem, we make the following assumptions obeying the economic theories.

Assumption 1. The remanufactured products are the same as new products made by raw materials, and there is no difference between their selling prices in demand markets in each period. This assumption comes from the example of single-use cameras of Eastman Kodak Company. The used cameras are typically upgraded to the quality of new ones, and both products can be perfectly substituted by each other [29].

Assumption 2. Compared with the production by raw materials, the manufacturers firstly choose to remanufacture the collected products because of cost saving. The assumption is commonly used in CLSC management literature to ensure the economy of remanufacturing.

Assumption 3. It is assumed that the manufacturers have carbon emission constraints during manufacturing and remanufacturing in each period. It is different from the case of traditional/forward supply chain, in which the carbon constraints are usually applied for multiperiod of time, for example, one year. However, in CLSC, it will take a relatively long time from product design, production, retailing, collection, and remanufacturing. The average return lags alone are often at least half a year [30].

Assumption 4. The carbon emission volume of remanufacturing a used product is lower than that of manufacturing a new product [27].

Assumption 5. The manufacturers and demand markets are separate in space and the place, and the distance between different tiers is included in the transaction cost functions. 
Assumption 6. The number of planning period is larger than product lifetime to illustrate the impact of product lifetime.

Assumption 7. One retailer only copes with one demand market.

Assumption 8. The production functions and transaction cost functions in the model are continuously differentiable and convex. This function property is required to be strictly satisfied in CLSC network equilibrium research $[6,19]$.

\subsection{Variables and Notations. Consider the following:}

$T$ : the number of total planning periods;

$Z$ : the product lifetime $(Z \geq 2)$, which means that the product can be manufactured once and remanufactured $Z-1$ times;

$t$ : a typical planning period, $t=1,2, \ldots, T$;

$s$ : a typical supplier, $s=1,2, \ldots, S$;

$m$ : a typical manufacturer, $m=1,2, \ldots, M$;

$n$ : a typical retailer, $n=1,2, \ldots, N$;

$k$ : a typical demand market, $k=1,2, \ldots, K$;

$\alpha$ : the collection rate of used products from demand market $k$; in this paper, we assume that $\alpha$ is a constant parameter in different periods;

$\beta^{r}$ : the average conversion rate of raw materials;

$\beta_{i}^{u}$ : the average remanufacturing conversion rate of used products in period $i, i=1, \ldots, \min \{t-1, Z-$ $1\}$, which in general satisfies $\beta_{i}^{u} \leq \beta_{i-1}^{u}, i=$ $2, \ldots, \min \{t-1, Z-1\}$. Moreover, in order to simplify the formulation expressions hereinafter, we introduce $\beta_{0}^{u}=1$;

$q_{s m}^{r}(t)$ : the amount of raw materials provided by supplier $s$ to manufacturer $m$ in period $t$; group all of $q_{s m}^{r}(t)$ into a $S M T$-dimension column vector $Q^{1}$;

$q_{s}^{r}(t)$ : the amount of raw materials provided by supplier $s$ to all manufacturers in period $t$; group all of $q_{s}^{r}(t)$ into a ST-dimension column vector $q_{1}^{r}$ and $q_{s}^{r}(t)=\sum_{m=1}^{M} q_{s m}^{r}(t)$;

$q_{m}^{r}(t)$ : the amount of raw materials that manufacturer $m$ uses for production in period $t$; group all of $q_{m}^{r}(t)$ into a $M T$-dimension column vector $q^{r}$;

$q_{m}^{u}(t)$ : the amount of collected products used in remanufacturing process in period $t(t \geq 2)$ and $q_{m}^{u}(t)=\sum_{k=1}^{K} q_{k m}^{u}(t-1)=$ $\sum_{n=1}^{N} \sum_{i=1}^{\min \{t-1, Z-1\}} \beta_{i-1}^{u} \cdots \beta_{0}^{u} \alpha^{i} q_{m n}^{r}(t-i)$; group all of $q_{m}^{u}(t)$ into a $M(T-1)$-dimension column vector $q^{u}$

$q_{m n}(t)$ : the transaction amount of new products between manufacturer $m$ and retailer $n$ in period $t$ group all of $q_{m n}(t)$ into a MNT-dimension column vector $Q^{2}$; $q_{m n}^{r}(t):$ the transaction amount of the new products made from raw materials between manufacturer $m$ and retailer $n$ in period $t$; group all of $q_{m n}^{r}(t)$ into a $M N T$-dimension column vector $Q^{3}$;

$q_{k m}^{u}(t)$ : the transaction amount of used products between manufacturer $m$ and demand market $n$ in period $t$; group all of $q_{k m}^{u}(t)$ into a $N M$-dimension column vector $Q^{4}(t)$, and group all of $q_{k m}^{u}(t)$ into a NMT-dimension column vector $Q^{4}$, and then we have $q_{k m}^{u}(t-1)=\sum_{i=1}^{\min \{t-1, Z-1\}} \beta_{i-1}^{u} \cdots \beta_{0}^{u} \alpha^{i} q_{m n}^{r}(t-i)$; $q_{n k}(t)$ : the transaction amount of products between manufacturer $m$ and retailer $n$ in period $t$; group all of $q_{n k}(t)$ into a NKT-dimension column vector $Q^{5}$;

$f_{s}^{r}\left(q_{1}^{r}(t)\right)$ : production cost of raw material by supplier $s$ in period $t$;

$f_{m}^{r}(t)=f_{m}^{r}\left(\beta_{r}, q^{r}(t)\right)$ : production cost of product by manufacturer $m$ in period $t$;

$f_{m}^{u}(t)=f_{m}^{u}\left(\beta_{i}^{u}, q_{m n}^{r}(t-i)\right)$ : remanufacturing cost of manufacturer $m$ in period $t, i=1, \ldots, \min \{t-1, Z-1\}$;

$c_{k m}^{u}(t)$ : transportation cost of used products undertaken by manufacturer $m$ in period $t(t \geq 2)$ from demand market $k$ to manufacturer $m$;

$c_{m}\left(q_{m}^{u}(t)\right)$ : disposal cost of manufacturer $m$ dealing with the collected products $q_{m}^{u}(t)$ in period $t(t \geq 2)$;

$I_{m}(t)$ : the inventory level of manufacturer $m$ in period $t$; group all of $I_{m}(t)$ into a $M T$-dimension column vector $I^{M}$;

$H_{m}(t)=H_{m}\left(I_{m}(t)\right)$ : the inventory cost function of manufacturer $m$ in period $t$;

$\rho_{s m}^{r}(t)$ : the transaction price between supplier $s$ and manufacturer $m$ in period $t$, an endogenous variable;

$\rho_{m n}(t)$ : the transaction price between manufacturer $m$ and retailer $n$ in period $t$, an endogenous variable;

$\bar{\rho}$ : unit disposal cost of used products by manufacturers, a constant;

$c_{m d}(t)=c_{m d}\left(\beta_{i}^{u}, q_{m}^{r}(t)\right)$ : transportation cost generated from moving the wastes to landfill by manufacturer $m$ in period $t(t \geq 2)$;

$\rho_{k m}^{u}(t)$ : the transaction price of used products between manufacturer $m$ and demand market $k$ in period $t(t \geq$ $2)$, an endogenous variable;

$c_{s m}^{r}(t)=c_{s m}^{r}\left(q_{s m}^{r}(t)\right)$ : the transaction cost undertaken by the supplier between manufacturer $m$ and supplier $s$ in period $t$;

$c_{m n}(t)=c_{m n}\left(q_{m n}(t)\right)$ : the transaction cost undertaken by the manufacturer between manufacturer $m$ and retailer $n$ in period $t$

$c_{n}\left(q_{m n}(t)\right)$ : handling cost of retailer $n$, mainly referring to package and exhibition cost;

$c_{n k}^{N}(t)=c_{n k}^{N}\left(q_{n k}(t)\right)$ : the transaction cost between retailer $n$ and demand market $k$ in period $t$ at retailer $n$ 
$c_{n k}^{K}(t)=c_{n k}^{K}\left(q_{n k}(t)\right)$ : the transaction cost between retailer $n$ and demand market $k$ in period $t$ at demand market $k$;

$\alpha_{n}\left(Q^{4}(t)\right)$ : the disutility function of consumer in demand market $k$ when he sells the used products to manufacturers;

$\rho_{n k}(t)$ : the price of unit product associated with retailer $n$ and demand market $k$ in period $t$, and all of $\rho_{n k}(t)$ are the elements of the NT-dimension column vector $\rho_{3}$;

$\rho_{4 k}(t)$ : the purchasing price of unit product associated with demand market $k$ in period $t$; all of $\rho_{4 k}(t)$ in period $t$ are the elements of the $K$-dimension column vector $\rho_{4}(t)$, and all of $\rho_{4 k}(t)$ belong to $K T$-dimension column vector $\rho_{4}$;

$d_{k}\left(\rho_{4}(t)\right)$ : the demand volume of the products with the demand price $\rho_{4 k}(t)$ at retailer $n$ in period $t$, which is a monotonic decreasing function depending on $\rho_{4 k}(t)$

$e_{x}$ : the carbon emissions when manufacturing and remanufacturing, in which $x=r$ denotes the case of production by unit raw materials and $x=u$ denotes the case of remanufacturing by used products; in general, $e_{u}<e_{r}$ is satisfied;

$B_{m}(t)$ : carbon emission cap of manufacturer $m$ in period $t$; group all of the $B_{m}(t)$ into a $M T$-dimension column vector $B$;

$s_{s m}(t)$ : the carbon tax paid by manufacturer $m$ in period $t$, an endogenous variable; group all of the $s_{s m}(t)$ into a $M T$-dimension column vector $s_{s}$.

\section{The Multiperiod CLSC Network Model}

4.1. The Optimal Behavior of Suppliers. The supplier $s$ supplies raw material to the manufactures in each period and seeks for the profit maximization in the planning horizons. Based on the notations described above, we can express the criterion for raw material supplier $s$ as follows:

$$
\begin{gathered}
\pi_{s}\left(q_{s m}^{r *}(t), q_{s}^{r *}(t)\right) \\
=\max \left\{\sum_{t=1}^{T} \sum_{m=1}^{M} \rho_{s m}^{r}(t) q_{s m}^{r}(t)-\sum_{t=1}^{T} \sum_{m=1}^{M} c_{s m}^{r}(t)\right. \\
\left.\quad-\sum_{t=1}^{T} f_{s}^{r}\left(q_{1}^{r}(t)\right)\right\} \\
\text { s.t. } \sum_{m=1}^{M} q_{s m}^{r}(t) \leq q_{s}^{r}(t) \\
\left(q_{s m}^{r}(t), q_{s}^{r}(t)\right) \in R_{+}^{S M+S}, \quad \forall s, m .
\end{gathered}
$$

The constraint (2) expresses that production amount of raw materials by supplier $s$ is higher than that of the transaction between the supplier $s$ and all the manufacturers.

It is assumed that all of the suppliers compete in a noncooperative fashion. Therefore, we can simultaneously express the optimal conditions of the suppliers as the variational inequality: determine $\left(Q^{1 *}, q_{1}^{r *}, \eta_{s}\right) \in R_{+}^{S M T+2 S T}$, satisfying

$$
\begin{aligned}
& \sum_{t=1}^{T} \sum_{s=1}^{S} \sum_{m=1}^{M} {\left[\frac{\partial c_{s m}^{r}(t)}{\partial q_{s m}^{r}(t)}-\rho_{s m}^{r}(t)+\eta_{s}(t)\right] } \\
& \times {\left[q_{s m}^{r}(t)-q_{s m}^{r *}(t)\right] } \\
&+\sum_{t=1}^{T} \sum_{s=1}^{S}\left[\frac{\partial f_{s}^{r}\left(q_{s}^{r}(t)\right)}{\partial q_{s}^{r}(t)}-\eta_{s}(t)\right] \\
& \times\left[q_{s}^{r}(t)-q_{s}^{r *}(t)\right] \\
&+\sum_{t=1}^{T} \sum_{s=1}^{S}\left[q_{s}^{r}(t)-\sum_{m=1}^{M} q_{s m}^{r}(t)\right] \times\left[\eta_{s}(t)-\eta_{s}^{*}(t)\right] \geq 0, \\
& \forall\left(Q^{1}, q_{1}^{r}, \eta_{s}\right) \in R_{+}^{S M T+2 S T} .
\end{aligned}
$$

In $(4), \eta_{s}(t)$ is the Lagrange multiplier corresponding to constraint (2) and $\eta_{s}$ is the $S T$-dimension column vector with the elements of $\eta_{s}(t)$.

4.2. The Optimal Behavior of Manufacturers. The manufacturer $m$ purchases the raw material from suppliers to make products, sells his new products to the retailers in every period, and manages inventory between different periods according to market demand; in the same time, the manufacturer $m$ collects the used products consumed by demand markets at the end of period $t$, which will be remanufactured in the next period $t+1$.

In the first planning period, the manufacturers just make products with virgin materials; from the second period, the manufacturers can make products with virgin materials and collected products simultaneously. With the consideration of the lifetime $Z$, the collected products can be remanufactured at most $Z-1$ times. When their remanufactured times arrive $Z-1$, they have no value anymore and must be disposed in an appropriate way.

For convenience, let $\beta_{i}=\beta_{i}^{u} \beta_{i-1}^{u} \cdots \beta_{1}^{u}, i=1, \ldots, \min \{t-$ $1, Z-1\}$. The profit function of manufacturer $m$ can be stated as follows:

$$
\begin{gathered}
\pi_{m}\left(q_{s m}^{r}(t), q_{m}^{r}(t), q_{m}^{u}(t), q_{m n}(t), q_{m n}^{r}(t), q_{n m}^{u}(t), I_{m}(t)\right) \\
=\max \left\{\sum_{t=1}^{T} \sum_{n=1}^{N} \rho_{m n}(t) q_{m n}(t)-\sum_{t=1}^{T} f_{m}^{r}(t)-\sum_{t=2}^{T} f_{m}^{u}(t)\right. \\
-\sum_{t=2}^{T} c_{m}\left(q_{m}^{u}(t)\right)-\sum_{t=1}^{T} \sum_{k=1}^{K} c_{n m}^{u}(t)-\sum_{t=1}^{T} H_{m}(t)
\end{gathered}
$$




$$
\begin{aligned}
& -\sum_{t=1}^{T} \sum_{m=1}^{M} \rho_{s m}^{r}(t) q_{s m}^{r}(t) \\
& -\sum_{t=1}^{T} \sum_{k=1}^{K} \rho_{n m}^{u}(t) q_{n m}^{u}(t)-c_{m n}(t) \\
& -\bar{\rho} \sum_{t=2}^{T} \sum_{i=1}^{\min \{t-1, Z-1\}} \beta_{i-1}\left(1-\beta_{i}^{u}\right) \alpha^{i} q_{m n}^{r}(t-i) \\
& -\sum_{t=2}^{T} \sum_{i=1}^{\min \{t-1, Z-1\}} c_{m d}(t) \\
& \left.-e_{r} \sum_{t=1}^{T} s_{m}(t) q_{m}^{r}(t)-e_{u} \sum_{t=2}^{T} s_{m}(t) q_{m}^{u}(t)\right\} \\
& \text { s.t. } I_{m}(t)+\sum_{n=1}^{N} q_{m n}(t)=\sum_{n=1}^{N} \sum_{i=1}^{\min (t-1, Z-1)} \beta_{i} \alpha^{i} q_{m n}^{r}(t-i) \\
& +\beta^{r} q_{m}^{r}+I_{m}(t-1) \\
& q_{m}^{u}(t)=\sum_{n=1}^{N} q_{n m}^{u}(t-1), \quad \forall t \geq 2 \\
& \sum_{n=1}^{N} q_{n m}^{u}(t-1)=\sum_{n=1}^{N} \sum_{i=1}^{\min \{t-1, Z-1\}} \beta_{i-1} \alpha^{i} q_{m n}^{r}(t-i) \quad \forall t \geq 2 \\
& \sum_{n=1}^{N} q_{m n}(t)=\sum_{n=1}^{N} q_{m n}^{r}(t) \\
& +\sum_{n=1}^{N} \sum_{i=1}^{\min \{t-1, Z-1\}} \beta_{i} \alpha^{i} q_{m n}^{r}(t-i) \\
& q_{m}^{r}(t) \leq \sum_{s=1}^{S} q_{s m}^{r}(t) \\
& q_{s m}^{r}(t), q_{m}^{r}(t), q_{m}^{u}(t), q_{m n}(t), q_{m n}^{r}(t), q_{n m}^{u}(t), I_{m}(t) \geq 0 \\
& \forall m, s, n \text {. }
\end{aligned}
$$

Constraint (6) describes that the current inventory plus the products amount selling to all retailers is equal to the sum of the products amount made from used products, virgin materials, and the inventory from the prior period. Constraint (7) expresses that the manufacturer $m$ collects the used products in period $t-1$ and remanufactures them in period $t$. The constraint (8) means that all the remanufacturable used products (in other words, their remanufacturing times are less than $Z-1$ ) are collected from the consumers by the manufacturer $m$ at the end of period $t-1$. Constraint (9) expresses that, apart from remanufacturing the used products, the manufacturers still need to produce with raw materials in each period.
Similar to $[6,20]$, all the manufactures compete in a noncooperative fashion, and each manufacturer seeks to maximize his profit based on the other manufacturers' optimal decisions, that is, deciding the amount of raw materials purchased from the suppliers, the used products collected from the consumers, the products sold to retailers, and the inventory transferring to next period in every period. Therefore, the optimal conditions of all the manufacturers can be described by the following variational inequality: determine $\left(q^{r *}, q^{u *}, Q^{1 *}, Q^{2 *}, Q^{3 *}, Q^{4 *}, I^{M *}, \gamma_{1}^{*}, \gamma_{2}^{*}, \gamma_{3}^{*}, \gamma_{4}^{*}, \gamma_{5}^{*}\right) \in \Omega^{M}$, satisfying

$$
\begin{aligned}
& \sum_{t=1}^{T} \sum_{m=1}^{M} \sum_{s=1}^{S}\left[\rho_{s m}^{r *}(t)-\gamma_{5 m}^{*}(t)\right] \times\left[q_{s m}^{r}(t)-q_{s m}^{r *}(t)\right] \\
& +\sum_{t=1}^{T} \sum_{m=1}^{M}\left[\frac{\partial f_{m}^{r}(t)}{\partial q_{m}^{r}(t)}-\beta^{r} \gamma_{1 m}^{*}(t)+\gamma_{5 m}^{*}(t)+e_{r} s_{m}^{*}(t)\right] \\
& \times\left[q_{m}^{r}(t)-q_{m}^{r *}(t)\right] \\
& +\sum_{t=2}^{T} \sum_{m=1}^{M}\left[\frac{\partial c_{m}\left(q_{m}^{u *}(t)\right)}{\partial q_{m}^{u}(t)}+\gamma_{2 m}^{*}(t-1)+e_{u} s_{m}^{*}(t)\right] \\
& \times\left[q_{m}^{u}(t)-q_{m}^{u *}(t)\right] \\
& +\sum_{t=1}^{T} \sum_{m=1}^{M} \sum_{n=1}^{N}\left[\frac{\partial c_{m n}(t)}{\partial q_{m n}(t)}+\gamma_{1 m}^{*}(t)+\gamma_{4 m}^{*}(t)-\rho_{m n}^{*}(t)\right] \\
& \times\left[q_{m n}(t)-q_{m n}^{*}(t)\right] \\
& +\sum_{t=1}^{T} \sum_{n=1}^{N} \sum_{m=1}^{M}\left[\frac{\partial c_{n m}^{u *}(t)}{\partial q_{n m}^{u}(t)}+\rho_{n m}^{u *}(t)-\gamma_{2 m}^{*}(t)-\gamma_{3 m}^{*}(t)\right] \\
& \times\left[q_{n m}^{u}(t)-q_{n m}^{u *}(t)\right] \\
& +\sum_{t=1}^{T} \sum_{n=1}^{N} \sum_{m=1}^{M}\left[\sum_{i=1}^{\min \{t, N-1\}}\left[\frac{\partial f_{m}^{u *}(t+i-1)}{\partial q_{m n}^{r}(t)}+\frac{c_{m d}(t-i)}{\partial q_{m n}^{r}(t)}\right]\right. \\
& -\sum_{i=0}^{\min \{t+1, Z-1\}} \beta_{i} \alpha^{i} \gamma_{4 m}^{*}(t+i) \\
& -\sum_{i=1}^{\min \{t+1, Z-1\}} \beta_{i} \alpha^{i} \gamma_{1 m}^{*}(t+i)+\bar{\rho} \\
& \times \sum_{i=1}^{\min \{t+1, Z-1\}} \beta_{i-1}\left(1-\beta_{i}^{u}\right) \alpha^{i} \\
& \left.+\sum_{i=1}^{\min \{t+1, Z-1\}} \beta_{i-1} \alpha^{i} \gamma_{3 m}^{*}(t+i-1)\right] \\
& \times\left[q_{m n}^{r}(t)-q_{m n}^{r *}(t)\right] \\
& +\sum_{t=1}^{T} \sum_{m=1}^{M}\left[\frac{\partial H_{m}^{*}(t)}{\partial I_{m}(t)}+\gamma_{1 m}^{*}(t)-\gamma_{1 m}^{*}(t+1)\right] \\
& \times\left[I_{m}(t)-I_{m}^{*}(t)\right]
\end{aligned}
$$




$$
\begin{aligned}
& +\sum_{t=1}^{T} \sum_{m=1}^{M}\left[\sum_{n=1}^{N} \sum_{i=1}^{\min \{t-1, Z-1\}} \beta_{i} \alpha^{i} q_{m n}^{r *}(t-i)\right. \\
& +\beta^{r} q_{m}^{r *}(t)+I_{m}^{*}(t-1) \\
& \left.-\sum_{n=1}^{N} q_{m n}^{*}(t)-I_{m}^{*}(t)\right] \\
& \times\left[\gamma_{1 m}(t)-\gamma_{1 m}^{*}(t)\right] \\
& +\sum_{t=1}^{T} \sum_{m=1}^{M}\left[\sum_{n=1}^{N} q_{n m}^{u *}(t)-q_{m}^{u *}(t+1)\right] \\
& \times\left[\gamma_{2 m}(t)-\gamma_{2 m}^{*}(t)\right] \\
& +\sum_{t=2}^{T} \sum_{m=1}^{M}\left[\sum_{n=1}^{N} q_{n m}^{u *}(t-1)\right. \\
& \left.-\sum_{n=1}^{N} \sum_{i=1}^{\min \{t-1, Z-1\}} \beta_{i-1} \alpha^{i} q_{m n}^{r *}(t-i)\right] \\
& \times\left[\gamma_{3 m}(t)-\gamma_{3 m}^{*}(t)\right] \\
& +\sum_{t=1}^{T} \sum_{m=1}^{M}\left[\sum_{n=1}^{N} q_{m n}^{r *}(t)+\sum_{n=1}^{N} \sum_{i=1}^{\min \{t-1, Z-1\}} \beta_{i} \alpha^{i} q_{m n}^{r *}(t-i)\right. \\
& \left.-\sum_{n=1}^{N} q_{m n}^{*}(t)\right] \times\left[\gamma_{4 m}(t)-\gamma_{4 m}^{*}(t)\right] \\
& +\sum_{t=1}^{T} \sum_{m=1}^{M}\left[\sum_{s=1}^{S} q_{s m}^{r *}(t)-q_{m}^{r *}(t)\right] \times\left[\gamma_{5 m}(t)-\gamma_{5 m}^{*}(t)\right] \\
& \geq 0 \\
& \forall\left(q^{r}, q^{u}, Q^{1}, Q^{2}, Q^{3}, Q^{4}, I^{M}, \gamma_{1}, \gamma_{2}, \gamma_{3}, \gamma_{4}, \gamma_{5}\right) \in \Omega^{M},
\end{aligned}
$$

where $\Omega^{M}=\left\{\left(q^{r}, q^{u}, Q^{1}, Q^{2}, Q^{3}, Q^{4}, I^{M}, \gamma_{1}, \gamma_{2}, \gamma_{3}, \gamma_{4}, \gamma_{5}\right) \in\right.$ $\left.R_{+}^{M T+M(T-1)+M S T+2 M N T+K M T+M T} \times R^{4 M T} \times R_{+}^{M T}\right\}$.

In (12), $\gamma_{1 m}(t), \gamma_{2 m}(t), \gamma_{3 m}(t), \gamma_{4 m}(t)$, and $\gamma_{5 m}(t)$ are the Lagrange multipliers corresponding to constraints (6), (7), (8), (9), and (10), and $\gamma_{1}, \gamma_{2}, \gamma_{3}, \gamma_{4}$, and $\gamma_{5}$ are the $M T$ dimension column vector with the elements of $\gamma_{1 m}(t), \gamma_{2 m}(t)$, $\gamma_{3 m}(t), \gamma_{4 m}(t)$, and $\gamma_{5 m}(t)$, respectively.

From the forth term of (12), we can find that when the transaction amount $q_{m n}^{*}(t)>0, \rho_{m n}^{*}(t)=\left(\partial c_{m n}^{*}(t) / \partial q_{m n}(t)\right)+$ $\gamma_{1 m}^{*}(t)+\gamma_{4 m}^{*}(t)$.

In the model, we consider the manufacturers' carbon emission constraints from the government in each period, and then the manufacturers' behaviors can be characterized by the following equation:

$$
B_{m}(t)-\left(e_{r} q_{m}^{r}(t)+e_{u} q_{m}^{u}(t)\right) \begin{cases}\geq 0, & s_{s m}(t)=0 \\ =0, & s_{s m}(t)>0 .\end{cases}
$$

Equation (13) describes that if the manufactures' carbon emission amount is lower than $B_{m}(t)$ in period $t$, the carbon tax is zero; on the other hand, if the manufactures' carbon emission amount is equal to $B_{m}(t)$ in period $t$, the manufacturers must pay taxes.

The above equilibrium condition corresponds to the following variational inequality: determine $s_{s}^{*} \in R_{+}^{M T}$, satisfying

$$
\begin{aligned}
\sum_{t=1}^{T} \sum_{m=1}^{M} & {\left[B_{m}^{*}(t)-\left(e_{r} q_{m}^{r *}(t)+e_{u} q_{m}^{u *}(t)\right)\right] } \\
\times & {\left[s_{s m}(t)-s_{s m}^{*}(t)\right] \geq 0, \quad \forall s_{s} \in R_{+}^{M T} . }
\end{aligned}
$$

In a word, the manufacturers' optimal behaviors must meet (10) and (14) simultaneously.

4.3. The Optimal Behavior of Retailers. The retailers need to decide how many products to purchase from every manufacturer and to sell to the consumers in demand markets to meet the random demand in markets.

For retailer $n$, the profits can be defined as follows:

$$
\begin{aligned}
& \pi_{n}\left(Q^{2}, Q^{5}\right) \\
& =\max \left(\sum_{t=1}^{T} \rho_{n k}(t) q_{n k}(t)\right. \\
& \quad-\sum_{t=1}^{T} c_{n}(t)-\sum_{t=1}^{T} \sum_{m=1}^{M} \rho_{m n}(t) q_{m n}(t) \\
& \left.\quad-\sum_{t=1}^{T} c_{n k}^{N}(t)\right) \\
& \text { s.t. } q_{n k}(t) \leq \sum_{m=1}^{M} q_{m n}(t) \\
& q_{m n}(t), q_{n k}(t) \geq 0, \quad \forall m, n, k .
\end{aligned}
$$

We also assume that the retailers compete in a noncooperative manner. The optimal behavior of each retailer is to maximize his profit when the other retailers' behaviors are given. So, the optimal conditions of all retailers can be described by variational inequality: determine $\left(Q^{2 *}, Q^{5 *}, \mu^{*}\right) \in \Omega^{N}$, satisfying

$$
\begin{aligned}
\sum_{t=1}^{T} & \sum_{n=1}^{N}\left[\frac{c_{n k}^{N *}(t)}{\partial q_{n k}(t)}-\rho_{n k}^{*}(t)+\mu_{n}^{*}(t)\right] \times\left[q_{n k}(t)-q_{n k}^{*}(t)\right] \\
& +\sum_{t=1}^{T} \sum_{n=1}^{N} \sum_{m=1}^{M}\left[\rho_{m n}^{*}(t)+\frac{\partial c_{n}^{*}(t)}{\partial q_{m n}}-\mu_{n}^{*}(t)\right]
\end{aligned}
$$




$$
\begin{array}{r}
\times\left[q_{m n}(t)-q_{m n}^{*}(t)\right] \\
+\sum_{t=1}^{T} \sum_{n=1}^{N}\left[\sum_{m=1}^{M} q_{m n}(t)-q_{n k}(t)\right] \times\left[\mu_{n}(t)-\mu_{n}^{*}(t)\right] \geq 0 \\
\forall\left(Q^{2}, Q^{5}, \mu\right) \in \Omega^{N}
\end{array}
$$

where $\Omega^{N}=\left\{\left(Q^{2}, Q^{5}, \mu\right) \in R_{+}^{M N T+N K T+N T}\right\}$.

In (18), $\mu_{n}(t)$ is the Lagrange multiplier corresponding to constraints (16) and $\mu$ is the NT-dimension column vector with the elements of $\mu_{n}(t)$.

From the first term of (18), we find that when the transaction volume $q_{n k}(t)>0, \rho_{n k}^{*}(t)=\left(c_{n k}^{N *}(t) / \partial q_{n k}(t)\right)+$ $\mu_{n}^{*}(t)$.

4.4. The Optimal Behavior of Demand Markets. In the forward supply chain, the consumers of each demand market decide to purchase the products from the retailer or not based on the appreciation level of products and also decide the purchasing price and amount.

According to literature [19], the transaction between the demand market and the retailer should satisfy a complement condition; that is, for some demand market $k$,

$$
d_{k}\left(\rho_{4}(t)\right) \begin{cases}=\sum_{n=1}^{N} q_{n k}(t), & \rho_{4 k}(t)>0 \\ \leq \sum_{n=1}^{N} q_{n k}(t), & \rho_{4 k}(t)=0\end{cases}
$$

Equation (19) illustrates that if the product amount supplied by each retailer is equal to that of demand in markets, then the transaction can proceed and the transaction price is positive. The demand amount depends on the transaction price paid by consumers in demand market $k$.

And also similar to [19], in the reverse supply chain, the demand markets' behavior should be characterized by the following equation:

$$
\alpha_{k}\left(Q^{4 *}(t)\right) \begin{cases}=\rho_{k m}^{u *}(t), & q_{k m}^{u}(t)>0, \\ \geq \rho_{k m}^{u *}(t), & q_{k m}^{u}(t)=0,\end{cases}
$$

where $\alpha_{n}\left(Q^{4}(t)\right)$ is the disutility of consumers in the demand market $n$ at period $t$. Equation (20) expresses that the higher collection price paid by manufacturers, the more used products the manufacturers collect. Moreover, the collected amount is lower than or equal to that of the products sold to the demand market, so the following constraint should be satisfied:

$$
\sum_{m=1}^{M} q_{k m}^{u}(t) \leq \sum_{n=1}^{N} q_{n k}(t)
$$

Let $\lambda_{k}(t)$ denote the Lagrange multiplier corresponding to (21), group all of $\lambda_{k}(t)$ into a $K T$-dimension column vector $\lambda$.
Besides the purchasing price paying to the retailers, the consumers must pay the transaction cost to obtain the products; hence, we have

$$
\rho_{n k}^{*}(t)+c_{n k}^{K *}(t) \begin{cases}=\rho_{4 k}(t), & q_{n k}^{*}(t)>0, \\ \geq \rho_{4 k}(t), & q_{n k}^{*}(t)=0 .\end{cases}
$$

Equations (19), (20), (21), and (22) can be described by the following variational inequality: determine $\left(Q^{4 *}, Q^{5 *}, \rho_{4}^{*}, \lambda^{*}\right) \in \Omega^{K}$, satisfying

$$
\begin{aligned}
\sum_{t=1}^{T} \sum_{n=1}^{N} \sum_{m=1}^{M}\left[\alpha_{n}\left(Q^{4 *}(t)\right)-\rho_{k m}^{u *}(t)+\lambda_{k}^{*}(t)\right] \\
\times\left[q_{k m}^{u}(t)-q_{k m}^{u *}(t)\right] \\
+\sum_{t=1}^{T} \sum_{n=1}^{N} \sum_{k=1}^{K}\left[\rho_{n k}^{*}(t)+c_{n k}^{K *}(t)-\lambda_{k}^{*}(t)\right] \\
\times\left[q_{n k}(t)-q_{n k}^{*}(t)\right] \\
+\sum_{t=1}^{T} \sum_{k=1}^{K}\left[\sum_{n=1}^{N} q_{n k}^{*}(t)-d_{k}\left(\rho_{4}^{*}(t)\right)\right] \\
\times\left[\rho_{4 k}(t)-\rho_{4 k}^{*}(t)\right] \\
+\sum_{t=1}^{T} \sum_{k=1}^{K}\left[\sum_{n=1}^{N} q_{n k}^{*}(t)-\sum_{m=1}^{M} q_{k m}^{u *}(t)\right] \\
\times\left[\lambda_{k}(t)-\lambda_{k}^{*}(t)\right] \geq 0 \\
\forall\left(Q^{4}, Q^{5}, \lambda\right) \in \Omega^{K},
\end{aligned}
$$

where $\Omega^{K}=\left\{\left(Q^{4}, Q^{5}, \rho_{4}, \lambda\right) \in R_{+}^{N M T+N K T+2 N T}\right\}$.

From the first term of inequality (23), we can conclude that when the transaction amount of collected products $q_{n m}^{u}(t) \geq 0$, the transaction price of collected products between manufacturers and demand markets $\rho_{n m}^{u *}(t)=$ $\alpha_{n}\left(Q^{4 *}(t)\right)+\lambda_{n}^{*}(t)$. In fact, since $\sum_{m=1}^{M} q_{m n}(t)>\sum_{m=1}^{M} q_{n m}^{u}(t)$ and $\lambda_{n}^{*}(t)=0$, we can get $\rho_{n m}^{u *}(t)=\alpha_{n}\left(Q^{4 *}(t)\right)$.

\subsection{The Equilibrium Conditions of Multiperiod CLSC Network}

Theorem 1. In equilibrium of the multiperiod CLSC network, the suppliers' optimal behaviors, as expressed by variational inequality (4), the manufacturers' optimal behaviors, as expressed by variational inequality (12) and (14), the retailers' optimal behaviors, as expressed by variational inequality (18), and the consumers' optimal behaviors, as expressed by variational inequality (23), must be satisfied simultaneously. One can state it in the following variational inequality: determine 
Discrete Dynamics in Nature and Society

9

$$
\begin{aligned}
& \left(q_{1}^{r *}, q^{r *}, q^{u *}, Q^{1 *}, Q^{2 *}, Q^{3 *}, Q^{4 *}, I^{M *}, s_{s}^{*}, \rho^{*}, \eta_{s}^{*}, \gamma_{1}^{*}, \gamma_{2}^{*}, \gamma_{3}^{*},\right. \\
& \left.\gamma_{4}^{*}, \gamma_{5}^{*}, \mu^{*}, \lambda^{*}\right) \in \Omega \text {, satisfying } \\
& \sum_{t=1}^{T} \sum_{s=1}^{S} \sum_{m=1}^{M}\left[\frac{\partial c_{s m}^{r *}(t)}{\partial q_{s m}^{r}(t)}+\eta_{s}^{*}(t)-\gamma_{5 m}^{*}(t)\right] \\
& \times\left[q_{s m}^{r}(t)-q_{s m}^{r *}(t)\right] \\
& +\sum_{t=1}^{T} \sum_{m=1}^{M}\left[\frac{\partial H_{m}^{*}(t)}{\partial I_{m}(t)}+\gamma_{1 m}^{*}(t)-\gamma_{1 m}^{*}(t+1)\right] \\
& \times\left[I_{m}(t)-I_{m}^{*}(t)\right] \\
& +\sum_{t=1}^{T} \sum_{m=1}^{M}\left[B_{m}(t)-\left(e_{r} q_{m}^{r *}(t)+e_{u} q_{m}^{u *}(t)\right)\right] \\
& \times\left[s_{s m}(t)-s_{s m}^{*}(t)\right] \\
& +\sum_{t=1}^{T} \sum_{s=1}^{S}\left[\frac{\partial f_{s}^{r *}\left(q_{s}^{r}(t)\right)}{\partial q_{s}^{r}(t)}-\eta_{s}^{*}(t)\right] \\
& \times\left[q_{s}^{r}(t)-q_{s}^{r *}(t)\right] \\
& +\sum_{t=1}^{T} \sum_{m=1}^{M}\left[\frac{\partial f_{m}^{r *}(t)}{\partial q_{m}^{r}(t)}-\beta^{r} \gamma_{1 m}^{*}(t)+e_{r} s_{m}^{*}(t)+\gamma_{5 m}^{*}(t)\right] \\
& \times\left[q_{m}^{r}(t)-q_{m}^{r *}(t)\right] \\
& +\sum_{t=2}^{T} \sum_{m=1}^{M}\left[\frac{\partial c_{m}\left(q_{m}^{u *}(t)\right)}{\partial q_{m}^{u}(t)}+\gamma_{2 m}^{*}(t-1)+e_{u} s_{m}^{*}(t)\right] \\
& \times\left[q_{m}^{u}(t)-q_{m}^{u *}(t)\right] \\
& +\sum_{t=1}^{T} \sum_{m=1}^{M} \sum_{n=1}^{N}\left[\frac{\partial c_{m n}^{*}(t)}{q_{m n}(t)}+\frac{\partial c_{n}^{*}(t)}{\partial q_{m n}}\right. \\
& \left.+\gamma_{1 m}^{*}(t)+\gamma_{4 m}^{*}(t)-\lambda_{k}^{*}(t)-\mu_{n}^{*}(t)\right] \\
& \times\left[q_{m n}(t)-q_{m n}^{*}(t)\right] \\
& +\sum_{t=1}^{T} \sum_{k=1}^{K} \sum_{m=1}^{M}\left[\frac{\partial c_{k m}^{u *}(t)}{\partial q_{k m}^{u}(t)}-\gamma_{2 m}^{*}(t)-\gamma_{3 m}^{*}(t)\right. \\
& \left.+\alpha_{n}\left(Q^{4 *}(t)\right)+\lambda_{k}^{*}(t)\right] \\
& \times\left[q_{k m}^{u}(t)-q_{k m}^{u *}(t)\right] \\
& +\sum_{t=1}^{T} \sum_{n=1}^{N} \sum_{m=1}^{M}\left[\sum_{i=1}^{\min \{t, N-1\}}\left[\frac{\partial f_{m}^{u *}(t+i-1)}{\partial q_{m n}^{r}(t)}+\frac{c_{m d}(t-i)}{\partial q_{m n}^{r}(t)}\right]\right. \\
& -\sum_{i=0}^{\min \{t+1, Z-1\}} \beta_{i} \alpha^{i} \gamma_{4 m}^{*}(t+i) \\
& -\sum_{i=1}^{\min \{t+1, Z-1\}} \beta_{i} \alpha^{i} \gamma_{1 m}^{*}(t+i) \\
& +\bar{\rho} \sum_{i=1}^{\min \{t+1, Z-1\}} \beta_{i-1}\left(1-\beta_{i}^{u}\right) \alpha^{i} \\
& \left.+\sum_{i=1}^{\min \{t+1, Z-1\}} \beta_{i-1} \alpha^{i} \gamma_{3 m}^{*}(t+i-1)\right] \\
& \times\left[q_{m n}^{r}(t)-q_{m n}^{r *}(t)\right] \\
& +\sum_{t=1}^{T} \sum_{n=1}^{N}\left[\frac{c_{n k}^{N *}(t)}{\partial q_{n k}(t)}+c_{n k}^{K *}(t)-\lambda_{k}^{*}(t)+\mu_{n}^{*}(t)\right] \\
& \times\left[q_{n k}(t)-q_{n k}^{*}(t)\right] \\
& +\sum_{t=1}^{T} \sum_{k=1}^{K}\left[\sum_{n=1}^{N} q_{n k}^{*}(t)-d_{k}\left(\rho_{4}^{*}(t)\right)\right] \\
& \times\left[\rho_{4 k}(t)-\rho_{4 k}^{*}(t)\right] \\
& +\sum_{t=1}^{T} \sum_{s=1}^{S}\left[q_{s}^{r *}(t)-\sum_{m=1}^{M} q_{s m}^{r *}(t)\right] \\
& \times\left[\eta_{s}(t)-\eta_{s}^{*}(t)\right] \\
& +\sum_{t=1}^{T} \sum_{m=1}^{M}\left[\sum_{n=1}^{N} \sum_{i=1}^{\min \{t-1, Z-1\}} \beta_{i} \alpha^{i} q_{m n}^{r *}(t-i)+\beta^{r} q_{m}^{r *}(t)\right. \\
& \left.+I_{m}^{*}(t-1)-\sum_{n=1}^{N} q_{m n}^{*}(t)-I_{m}^{*}(t)\right] \\
& \times\left[\gamma_{1 m}(t)-\gamma_{1 m}^{*}(t)\right] \\
& +\sum_{t=1}^{T} \sum_{m=1}^{M}\left[\sum_{n=1}^{N} q_{n m}^{u *}(t)-q_{m}^{u *}(t+1)\right] \\
& \times\left[\gamma_{2 m}(t)-\gamma_{2 m}^{*}(t)\right] \\
& +\sum_{t=2}^{T} \sum_{m=1}^{M}\left[\sum_{n=1}^{N} q_{n m}^{u *}(t-1)\right. \\
& \left.-\sum_{n=1}^{N} \sum_{i=1}^{\min \{t-1, Z-1\}} \beta_{i-1} \alpha^{i} q_{m n}^{r *}(t-i)\right] \\
& \times\left[\gamma_{3 m}(t)-\gamma_{3 m}^{*}(t)\right] \\
& +\sum_{t=1}^{T} \sum_{m=1}^{M}\left[\sum_{n=1}^{N} q_{m n}^{r *}(t)\right. \\
& \left.+\sum_{n=1}^{N} \sum_{i=1}^{\min \{t-1, Z-1\}} \beta_{i} \alpha^{i} q_{m n}^{r *}(t-i)-\sum_{n=1}^{N} q_{m n}^{*}(t)\right] \\
& \times\left[\gamma_{4 m}(t)-\gamma_{4 m}^{*}(t)\right] \\
& +\sum_{t=1}^{T} \sum_{m=1}^{M}\left[\sum_{s=1}^{S} q_{s m}^{r *}(t)-q_{m}^{r *}(t)\right]
\end{aligned}
$$




$$
\begin{gathered}
\times\left[\gamma_{5 m}(t)-\gamma_{5 m}^{*}(t)\right] \\
+\sum_{t=1}^{T} \sum_{n=1}^{N}\left[\sum_{m=1}^{M} q_{m n}(t)-q_{n k}(t)\right] \\
\times\left[\mu_{n}(t)-\mu_{n}^{*}(t)\right] \\
+\sum_{t=1}^{T} \sum_{k=1}^{K}\left[q_{n k}^{*}(t)-\sum_{m=1}^{M} q_{k m}^{u *}(t)\right] \\
\times\left[\lambda_{k}(t)-\lambda_{k}^{*}(t)\right] \geq 0, \\
\forall\left(q_{1}^{r}, q^{r}, q^{u}, Q^{1}, Q^{2}, Q^{3}, Q^{4}, I^{M}, s_{s},\right. \\
\left.v, \rho, \eta_{s}, \gamma_{1}, \gamma_{2}, \gamma_{3}, \gamma_{4}, \gamma_{5}, \mu, \lambda\right) \in \Omega,
\end{gathered}
$$

where $\Omega=\Omega^{S} \times \Omega^{M} \times \Omega^{N} \times \Omega^{K}$.

4.6. Solving Algorithm and Parameter Setting. For easy formulation hereinafter, we group the terms of the multiplication signs in inequality (24) into a column vector $F(y)=$ $\left\{F_{s m t}^{1}, F_{s t}^{2}, F_{m t}^{3}, F_{m(t-1)}^{4}, F_{m n t}^{5}, F_{m n t}^{6}, F_{k m t}^{7}, F_{m t}^{8}, F_{m t}^{9}, F_{n t}^{10}, F_{n t}^{11}, F_{s t}^{12}\right.$, $\left.F_{m t}^{13}, F_{m t}^{14}, F_{m t}^{15}, F_{m t}^{16}, F_{m t}^{17}, F_{n t}^{18}, F_{n t}^{19}\right\}_{\forall s, m, n, k, t}$ and introduce $y=$ $\left(q_{1}^{r}, q^{r}, q^{u}, Q^{1}, Q^{2}, Q^{3}, Q^{4}, I^{M}, s_{s}, v, \rho, \eta_{s}, \gamma_{1}, \gamma_{2}, \gamma_{3}, \gamma_{4}, \gamma_{5}, \mu, \lambda\right)$ $\epsilon \Omega$; thus, we can rewrite the variational inequality problem (24) in the standard form: determine $y^{*}=\left(q_{1}^{r *}, q^{r *}, q^{u *}, Q^{1 *}, Q^{2 *}, Q^{3 *}, Q^{4 *}, I^{M *}, s_{s}^{*}, v^{*}, \rho^{*}, \eta_{s}^{*}, \gamma_{1}^{*}\right.$, $\left.\gamma_{2}^{*}, \gamma_{3}^{*}, \gamma_{4}^{*}, \gamma_{5}^{*}, \mu^{*}, \lambda^{*}\right)$, satisfying

$$
F(y)^{T} \cdot\left(y-y^{*}\right) \geq 0, \quad \forall y \in \Omega .
$$

In order to solve the variational inequality (25), we have several algorithms to select, for example, the modified project contraction algorithm [31], logarithmic-quadratic proximal prediction-correction method [32]. In this paper, we employ the modified project contraction algorithm to solve the problem for two reasons. Firstly, the modified project contraction algorithm provides an iterative solution framework that can deal with variational inequalities defined on polyhedral sets and get the optimal solutions and Lagrangian multipliers simultaneously. So, it satisfies all the requirements of a solution method for our model. Secondly, the design of its iterative steps is much simpler than that of logarithmicquadratic proximal prediction-correction method. Set the related parameters of the modified project contraction algorithm as follows: the original value of decision variables and Lagrange multipliers is set to 1 ; the convergence criterion, for example, the absolute value of difference of decision variables and Lagrange multipliers between two steps, is lower than or equal to $10^{-8}$.

\section{Numerical Examples}

Now, we consider a CLSC network with two suppliers, two manufacturers, two retailers, and two demand markets, the lifetime of products is two or three, and the planning horizon is five. In this construction, we give some numerical examples to illustrate the efficiency of our model and analyze the influence of some parameters to obtain managerial insights. The related cost functions are given as follows.

Suppliers' raw material producing cost functions:

$$
\begin{array}{r}
f_{s}^{r}\left(q_{1}^{r}(t)\right)=(1+4 t) q_{s}^{r}(t)^{2}+q_{s}^{r}(t)+1, \\
s=1,2 ; \quad t=1,2,3,4,5 ;
\end{array}
$$

manufacturers' production cost functions using raw material:

$$
\begin{aligned}
& f_{m}^{r}(t)=(0.5+1.5 t)\left(\beta^{r} q_{m}^{r}(t)\right)^{2} \\
&+\beta^{r} q_{m}^{r}(t) \beta^{r} q_{3-m}^{r}(t)+2 \beta^{r} q_{m}^{r}(t), \\
& m=1,2 ; \quad t=1,2,3,4,5 ;
\end{aligned}
$$

manufacturers' remanufacturing cost functions using collected products:

$$
\begin{aligned}
& f_{m}^{u}(2)=4.5\left(\beta_{1}^{u} \alpha \sum_{n=1}^{2} q_{m n}^{r}(1)\right)^{2}+1.5\left(\beta_{1}^{u} \alpha \sum_{n=1}^{2} q_{m n}^{r}(1)\right), \\
& m=1,2 ; \\
& f_{m}^{u}(t) \\
& =(4.5-0.5 t) \\
& \quad \times\left(\beta_{1}^{u} \alpha \sum_{n=1}^{2} q_{m n}^{r}(t-1)+2 \delta \beta_{2}^{u} \beta_{1}^{u} \alpha^{2} \sum_{n=1}^{2} q_{m n}^{r}(t-2)\right)^{2} \\
& +1.5\left(\beta_{1}^{u} \alpha \sum_{n=1}^{2} q_{m n}^{r}(t-1)+2 \delta \beta_{2}^{u} \beta_{1}^{u} \alpha^{2} \sum_{n=1}^{2} q_{m n}^{r}(t-2)\right), \\
& m=1,2 ; \quad t=3,4,5 ;
\end{aligned}
$$

the manufacturers' inventory cost functions:

$$
\begin{array}{r}
H_{m}(t)=\left(2+(-1)^{t} 0.5\right) I_{m}(t), \\
m=1,2 ; \quad t=1,2,3,4,5 ;
\end{array}
$$

the manufacturers' disposal cost functions dealing with the collected products:

$$
\begin{array}{r}
c_{m}\left(q_{m}^{u}(t)\right)=2.5 q_{m}^{u}(t)^{2}+q_{m}^{u}(t)+2, \\
m=1,2 ; \quad t=2,3,4,5 ;
\end{array}
$$

the transportation cost functions from demand markets to manufacturers:

$$
\begin{aligned}
& c_{n m}^{u}(t)=0.5 q_{n m}^{u}(t)^{2}+3 q_{n m}^{u}(t)+1, \\
& m=1,2 ; \quad n=1,2 ; \quad t=2,3,4,5 ;
\end{aligned}
$$


the manufacturers' transportation cost functions to move the waste of disposal products to landfill:

$$
\begin{aligned}
& c_{m d}(2)= .5\left[\left(1-\beta_{1}^{u}\right) \alpha \sum_{n=1}^{2} q_{m n}^{r}(1)\right]^{2} \\
&+ 3.5\left(1-\beta_{1}^{u}\right) \alpha \sum_{n=1}^{2} q_{m n}^{r}(1), \\
& c_{m d}(t)=0.5\left[\delta\left(1-\beta_{2}^{u}\right) \beta_{1}^{u} \alpha^{2} \sum_{n=1}^{2} q_{m n}^{r}(t-2)\right. \\
&\left.+\left(1-\beta_{1}^{u}\right) \alpha \sum_{n=1}^{2} q_{m n}^{r}(t-1)\right]^{2} \\
&+3.5\left[\delta\left(1-\beta_{2}^{u}\right) \beta_{1}^{u} \alpha^{2} \sum_{n=1}^{2} q_{m n}^{r}(t-2)+\left(1-\beta_{1}^{u}\right) \alpha\right. \\
& \\
&\left.\quad \times \sum_{n=1}^{2} q_{m n}^{r}(t-1)\right]
\end{aligned}
$$$$
\text { for } t=3,4,5 ; \quad m=1,2 \text {; }
$$

the consumers' disutility functions in demand markets:

$$
\begin{gathered}
\alpha_{n}\left(Q^{4}(t)\right)=0.5 \sum_{m=1}^{2} \sum_{n=1}^{2} q_{n m}^{u}(t), \\
\text { for } n=1,2 ; \quad t=1,2,3,4,5 ;
\end{gathered}
$$

the transaction cost functions undertaken by the supplier between suppliers and manufacturers:

$$
\begin{aligned}
& c_{s m}^{r}(t)=0.5\left(q_{s m}^{r}(t)\right)^{2}+q_{s m}^{r}(t), \\
& \text { for } s=1,2 ; \quad m=1,2 ; \quad t=1,2,3,4,5 ;
\end{aligned}
$$

the transaction cost functions undertaken by the manufacturer between manufacturers and retailers:

$$
\begin{aligned}
& c_{m n}(t)=\left(q_{m n}(t)\right)^{2}+3 q_{m n}(t)+0.5, \\
& \text { for } m=1,2 ; \quad n=1,2 ; \quad t=1,2,3,4,5 ;
\end{aligned}
$$

the disposal functions of retailers:

$$
\begin{aligned}
& c_{n}\left(Q^{2}\right)=0.25\left(\sum_{m=1}^{M} q_{m n}(t)\right)^{2}, \\
& \text { for } n=1,2 ; \quad t=1,2,3,4,5 ;
\end{aligned}
$$

the transaction cost functions undertaken by retailer $n$ to demand market $k$ :

$$
\begin{aligned}
& c_{n k}^{N}(t)=0.5\left(q_{n k}(t)\right)^{2}+q_{n k}(t)+1, \\
& n=1,2 ; \quad k=1,2 ; \quad t=1,2,3,4,5 ;
\end{aligned}
$$

the transaction cost functions undertaken by demand markets purchasing products from retailers:

$$
\begin{aligned}
& c_{n k}^{K}(t)=q_{n k}(t)+0.5, \\
& n=1,2 ; \quad t=1,2,3,4,5 ;
\end{aligned}
$$

the demand functions of the consumer markets:

$$
\begin{array}{r}
d_{k}\left(\rho_{t}^{D}\right)=-(2.2-0.4 t) \rho_{3-k}^{D}(t)-2 \rho_{k}^{D}(t)+120, \\
k=1,2, \quad t=1,2,3,4,5 .
\end{array}
$$

In order to illustrate the impact of lifetime on equilibrium results, we introduce $\delta$, a Boolean parameter, to represent two cases of lifetime values: $\delta=0$ denotes that the product lifetime is two, and $\delta=1$ denotes that the product lifetime is three. The total planning horizon is five.

5.1. Numerical Example 1. When $\delta=0$, for example, the product lifetime is $2, \bar{\rho}=1, \beta^{r}=1, \beta_{1}^{u}=0.9$, and $\beta_{2}^{u}=0.6$, we analyze the effect of the collection rate $\alpha$ on the equilibrium results given in Table 1, in which the data in each column are the equilibrium solutions corresponding to a value of $\alpha$ and the data in each row are the optimal values of main variables.

From Table 1, we can find that when $\alpha$ increases, the volume of raw material $q_{s}^{r}$ (equal to $q_{m}^{r}$ ) supplied to manufacturers, the used products $q_{m}^{u}$ collected by manufacturers, and the transaction $q_{m n}$ between manufacturers and retailers increase too, so the increase of $\alpha$ stimulates the transaction of the network. Moreover, in order to obtain and remanufacture more used products, the manufacturers and retailers should sell more products and hence collect more used products at the end of each period, so that the transaction price $\rho_{n}$ between retailers and demand markets is decreasing all the time except the last period. This point characterizes the dynamic network fully in which the players are foresighted rather than shortsighted.

From Table 1, we also find that $I_{m}(t)$ decreases when $\alpha$ increases. It is because of the transaction volume increasing, and the manufacturers have no motivation to transfer more inventories to next period, and $I_{m}(5)=0$ means all the surplus products are sold out in the last period.

In the following, we analyze the impact of $\alpha$ increasing on the profits of players in the CLSC network. The suppliers' and retailers' profits increase because of their transaction volume with manufacturers increasing. The profits of manufacturers increase at the beginning but then decrease, and the maximum values appear at about the point 0.15 of $\alpha$, so we must explain this interesting phenomena. When $\alpha$ increases, the amount of collected products also increases; therefore, the collection price increases; that is, the manufacturers must pay more to demand markets for obtaining extra used products. When the collection price reaches a threshold, the cost saving via remanufacturing cannot make up the increased collection cost, so the manufacturers' profits reach the maximum and then decrease when the price continues to increase.

5.2. Numerical Example 2. When $\delta=1$, for example, the product lifetime is $3, \bar{\rho}=1, \beta^{r}=1, \beta_{1}^{u}=0.9$, and $\beta_{2}^{u}=0.6$, we 
TABLE 1: $\delta=0$, the CLSC network equilibrium results when $\alpha$ increases.

\begin{tabular}{|c|c|c|c|c|c|c|}
\hline$\alpha$ & 0.05 & 0.1 & 0.15 & 0.2 & 0.25 & 0.3 \\
\hline & 3.0927 & 3.1929 & 3.2862 & 3.3723 & 3.4510 & 3.5219 \\
\hline$q_{s}^{r}, q_{m}^{r}$ & 1.9756 & 2.0357 & 2.0917 & 2.1434 & 2.1906 & 2.2332 \\
\hline$s=1,2$ & 1.5540 & 1.5970 & 1.6369 & 1.6738 & 1.7076 & 1.7380 \\
\hline \multirow[t]{2}{*}{$m=1,2$} & 1.2753 & 1.3087 & 1.3398 & 1.3685 & 1.3948 & 1.4184 \\
\hline & 1.1344 & 1.1617 & 1.1871 & 1.2106 & 1.2321 & 1.2514 \\
\hline & 0.0162 & 0.0463 & 0.0901 & 0.1469 & 0.2161 & 0.2965 \\
\hline$q_{m}^{u}$ & 0.0460 & 0.1060 & 0.1781 & 0.2612 & 0.3552 & 0.4614 \\
\hline \multirow[t]{2}{*}{$m=1,2$} & 0.0737 & 0.1595 & 0.2537 & 0.3517 & 0.4480 & 0.5358 \\
\hline & 0.1339 & 0.2871 & 0.4638 & 0.6695 & 0.9106 & 1.1957 \\
\hline \multirow{5}{*}{$\begin{array}{l}q_{m n}^{r} \\
m=1,2 ; \\
n=1,2\end{array}$} & 0.1620 & 0.2317 & 0.3002 & 0.3672 & 0.4322 & 0.4941 \\
\hline & 0.4599 & 0.5299 & 0.5937 & 0.6530 & 0.7104 & 0.7690 \\
\hline & 0.7374 & 0.7977 & 0.8455 & 0.8792 & 0.8961 & 0.8929 \\
\hline & 1.3393 & 1.4353 & 1.5460 & 1.6737 & 1.8212 & 1.9928 \\
\hline & 1.8174 & 1.6534 & 1.4854 & 1.3112 & 1.1281 & 0.9325 \\
\hline \multirow{5}{*}{$\begin{array}{l}q_{m n} \\
m=1,2 \\
n=1,2\end{array}$} & 0.1620 & 0.2317 & 0.3002 & 0.3672 & 0.4322 & 0.4941 \\
\hline & 0.4672 & 0.5507 & 0.6342 & 0.7191 & 0.8076 & 0.9024 \\
\hline & 0.7581 & 0.8454 & 0.9257 & 0.9967 & 1.0559 & 1.1006 \\
\hline & 1.3725 & 1.5071 & 1.6602 & 1.8319 & 2.0229 & 2.2339 \\
\hline & 1.8776 & 1.7826 & 1.6942 & 1.6125 & 1.5379 & 1.4706 \\
\hline \multirow{5}{*}{$\begin{array}{l}I_{m} \\
m=1,2\end{array}$} & 2.7687 & 2.7295 & 2.6858 & 2.6378 & 2.5866 & 2.5337 \\
\hline & 3.8245 & 3.7055 & 3.5901 & 3.4751 & 3.3564 & 3.2288 \\
\hline & 3.9037 & 3.7070 & 3.5359 & 3.3906 & 3.2718 & 3.1809 \\
\hline & 2.5003 & 2.1451 & 1.7837 & 1.4118 & 1.0241 & 0.6136 \\
\hline & 0 & 0 & 0 & 0 & 0 & 0 \\
\hline \multirow{5}{*}{$\begin{array}{l}\rho_{n} \\
n=1,2\end{array}$} & 30.6697 & 30.4936 & 30.3205 & 30.1512 & 29.9870 & 29.8307 \\
\hline & 33.5850 & 33.3687 & 33.1526 & 32.9328 & 32.7037 & 32.4584 \\
\hline & 37.4783 & 37.2456 & 37.0315 & 36.8421 & 36.6842 & 36.5651 \\
\hline & 41.8530 & 41.4803 & 41.0565 & 40.5809 & 40.0521 & 39.4675 \\
\hline & 48.5833 & 48.8597 & 49.1170 & 49.3546 & 49.5717 & 49.7674 \\
\hline \multirow{5}{*}{$\begin{array}{l}\rho_{k m}^{u} \\
k=1,2\end{array}$} & 0.0162 & 0.0463 & 0.0901 & 0.1469 & 0.2161 & 0.2965 \\
\hline & 0.0460 & 0.1060 & 0.1781 & 0.2612 & 0.3552 & 0.4614 \\
\hline & 0.0737 & 0.1595 & 0.2537 & 0.3517 & 0.4480 & 0.5358 \\
\hline & 0.1339 & 0.2871 & 0.4638 & 0.6695 & 0.9106 & 1.1957 \\
\hline & 0 & 0 & 0 & 0 & 0 & 0 \\
\hline$\pi_{s}, s=1,2$ & 32.2546 & 34.7208 & 37.0795 & 39.3119 & 41.3978 & 43.3149 \\
\hline$\pi_{m}, m=1,2$ & 75.9138 & 77.0719 & 77.1677 & 75.8899 & 72.8294 & 67.4213 \\
\hline$\pi_{n}, n=1,2$ & 18.6856 & 19.5621 & 20.9267 & 22.8044 & 25.2330 & 28.2688 \\
\hline Total profit & 126.8549 & 131.3548 & 135.1739 & 138.0062 & 139.4602 & 139.0050 \\
\hline
\end{tabular}

analyze the impact of the collection rate $\alpha$ on the equilibrium results. The equilibrium results are shown in Table 2.

In Table 2, the changing trends of some variables such as $q_{s}^{r}, q_{m}^{r}, q_{m}^{u}, q_{m n}, I_{m}$, and profits of suppliers, manufacturers, and retailers are similar to those in Table 1 depending on $\alpha$, and, in turn, we will pay more attention to the differences between the two tables.

In respect to the profits of suppliers and retailers, there are changes but not large in the course of $\alpha$ increasing. But the profits of manufacturers change dramatically. The maximum value of manufacturers' profit is 77.1677 in Table 1, which is at about the point 0.1 of $\alpha$ and larger than the corresponding value 76.3586 in Table 2. This phenomenon shows that the smaller the product lifetime is, the more profits the manufacturers can earn, which means that the environmental and resource targets are different from those of the enterprise to seek maximized profits.

For CLSC, the maximum total profits are 139.4602 and 136.4576 at the points 0.25 and 0.2 of $\alpha$ when $\delta=0$ and $\delta=1$, respectively. The maximum profits of the whole CLSC and the manufacturers appear in different points of $\alpha$, so the objects of the manufactures and the whole CLSC are also different. If the manufacturers can give up a part of interests, then the performance of CLSC will be better.

Moreover, we compare the CLSC profits in two cases of $\delta=0$ and $\delta=1$ when $\alpha$ is set to be a same value. It can be seen that when $\alpha \leq 0.1$, the CLSC profit with $Z=3$ is larger than that with $Z=2$. However, when $\alpha \geq 0.15$, the quantitative relationship between the two is opposite. The phenomenon shows clearly that more product lifetime is not always a benefit to the CLSC. Too high collection rate will result in the fact that the collection burden of the manufacturers aggravates and the operational efficiency of the CLSC reduces, although it contributes to the cost saving by remanufacturing. Therefore, the government should set the collection rate in a suitable region based on the manufacturers' collection cost structure and benefits from remanufacturing. 
TABLE 2: $\delta=1$, the CLSC network equilibrium states when $\alpha$ increases.

\begin{tabular}{|c|c|c|c|c|c|c|}
\hline$\alpha$ & 0.05 & 0.1 & 0.15 & 0.2 & 0.25 & 0.3 \\
\hline \multirow{5}{*}{$\begin{array}{l}q_{s}^{r}, q_{m}^{r} \\
s=1,2 ; \\
m=1,2\end{array}$} & 3.1073 & 3.2281 & 3.3470 & 3.4627 & 3.5734 & 3.6772 \\
\hline & 1.9844 & 2.0568 & 2.1282 & 2.1976 & 2.2641 & 2.3263 \\
\hline & 1.5603 & 1.6120 & 1.6630 & 1.7126 & 1.7600 & 1.8045 \\
\hline & 1.2802 & 1.3205 & 1.3601 & 1.3987 & 1.4356 & 1.4702 \\
\hline & 1.1384 & 1.1713 & 1.2037 & 1.2353 & 1.2655 & 1.2938 \\
\hline \multirow{4}{*}{$\begin{array}{l}q_{m}^{u} \\
m=1,2\end{array}$} & 0.0177 & 0.0530 & 0.1070 & 0.1805 & 0.2738 & 0.3870 \\
\hline & 0.0483 & 0.1175 & 0.2087 & 0.3222 & 0.4572 & 0.6116 \\
\hline & 0.0778 & 0.1802 & 0.3105 & 0.4721 & 0.6677 & 0.8996 \\
\hline & 0.1358 & 0.2946 & 0.4802 & 0.6971 & 0.9499 & 1.2440 \\
\hline \multirow{5}{*}{$\begin{array}{l}q_{m n}^{r} \\
m=1,2 ; \\
n=1,2\end{array}$} & 0.1766 & 0.2652 & 0.3568 & 0.4512 & 0.5476 & 0.6450 \\
\hline & 0.4748 & 0.5637 & 0.6475 & 0.7242 & 0.7912 & 0.8452 \\
\hline & 0.7564 & 0.8500 & 0.9476 & 1.0498 & 1.1573 & 1.2711 \\
\hline & 1.3243 & 1.3965 & 1.4729 & 1.5537 & 1.6393 & 1.7302 \\
\hline & 1.8031 & 1.6190 & 1.4261 & 1.2244 & 1.0139 & 0.7944 \\
\hline \multirow{5}{*}{$\begin{array}{l}q_{m n} \\
m=1,2 \\
n=1,2\end{array}$} & 0.1766 & 0.2652 & 0.3568 & 0.4512 & 0.5476 & 0.6450 \\
\hline & 0.4828 & 0.5876 & 0.6957 & 0.8054 & 0.9144 & 1.0194 \\
\hline & 0.7780 & 0.9022 & 1.0394 & 1.1899 & 1.3538 & 1.5306 \\
\hline & 1.3590 & 1.4760 & 1.6087 & 1.7583 & 1.9264 & 2.1145 \\
\hline & 1.8637 & 1.7492 & 1.6365 & 1.5268 & 1.4218 & 1.3234 \\
\hline \multirow{5}{*}{$\begin{array}{l}I_{m} \\
m=1,2\end{array}$} & 2.7541 & 2.6977 & 2.6333 & 2.5603 & 2.4783 & 2.3871 \\
\hline & 3.7888 & 3.6272 & 3.4665 & 3.3094 & 3.1598 & 3.0230 \\
\hline & 3.8363 & 3.5392 & 3.2343 & 2.9224 & 2.6053 & 2.2853 \\
\hline & 2.4679 & 2.0666 & 1.6486 & 1.2136 & 0.7622 & 0.2951 \\
\hline & 0 & 0 & 0 & 0 & 0 & 0 \\
\hline$\pi_{s}, s=1,2$ & 32.6103 & 35.6032 & 38.6502 & 41.7106 & 44.7290 & 47.6346 \\
\hline$\pi_{m}, m=1,2$ & 75.7360 & 76.3586 & 75.2496 & 71.6741 & 64.7021 & 53.2055 \\
\hline$\pi_{n}, n=1,2$ & 18.5700 & 19.4041 & 20.8727 & 23.0729 & 26.1039 & 30.0609 \\
\hline Total profit & 126.9163 & 131.3659 & 134.7725 & 136.4576 & 135.5350 & 130.9010 \\
\hline
\end{tabular}

5.3. Numerical Example 3. When $B_{m}(1)=3, \delta=0, \bar{\rho}=1$, $\beta^{r}=1, \beta_{1}^{u}=0.9$, and $\beta_{2}^{u}=0.6$, we analyze the impact of the collection rate $\alpha$ on the equilibrium results. The profits of various players in CLSC are shown in Figure 2.

From Figure 2, we can make a conclusion that as $\alpha$ increases, the profits of suppliers and retailers increase while the profit of manufacturers increases at the beginning and then decreases. This is the same as the above analysis in Table 1. The maximum value of the profit of manufacturer differs at another point of $\alpha$; that is, the maximum value point in Table 1 is at $\alpha=0.15$ but at $\alpha=0.1$ in Figure 2. This is because of the existence of carbon emission cap in the 1st period; the profits of all players are lower than that without carbon emission cap by comparing Figure 2 with Table 1.

5.4. Numerical Example 4. When $\alpha=0.25$ and $\delta=0, \bar{\rho}=1$, $\beta^{r}=1, \beta_{1}^{u}=0.9$, and $\beta_{2}^{u}=0.6$, we analyze the effect of different carbon emission caps of the first 3 periods on the equilibrium results shown in Table 3.

Table 3 presents main variables associated with different carbon caps. As mentioned above, $s_{m}$ are the Lagrange multiplier associated with the carbon cap, and $s_{m}>0$ means that the carbon emission reaches the cap. We compare the first 2 columns in Table 3 and note that when the carbon emission cap of the 1st period becomes smaller, Lagrange multiplier associated with the 1st period is larger, while the amounts of raw material supplied to the manufacturers are larger except in the 1st period due to the carbon emission constraints. The amount of collected products of the manufacturers is smaller in all planning periods.

The profits of all players in the network decrease when the cap decreases. So, the carbon emission constraint is harmful to the CLSC in the economic aspect without considering the environmental target.

Now, we compare the 1st column with the 3rd and 4th columns, in which the carbon emission cap in the 1st period is fixed, and in the 2nd period it appears and then becomes smaller. The amount of raw materials supplied to the manufacturers is larger than the 3rd period because there are no constraints since this period. The amount of collected products by the manufacturers is larger in the 1st period and smaller in the other periods. The profits of all players in the network decrease when the cap of the 2 nd period decreases.

Finally, we compare the 3rd column with the 5 th and 6 th columns. The amount of raw materials supplied to the manufacturers is larger than the 4 th period with no constraints since this period. The amount of collected products by the manufacturers is larger in the 2nd period and smaller in other periods. The profits of all players in the network also decrease.

From the analysis above, we can make the following conclusion: when setting carbon emission caps in some periods, the supply amounts of raw materials in these periods 


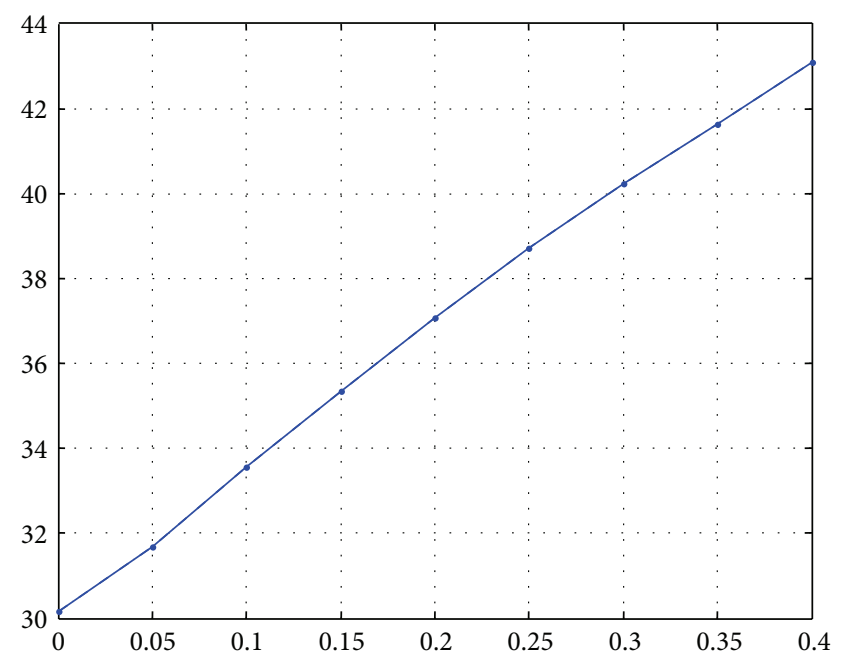

$\rightarrow$ Profit of suppliers

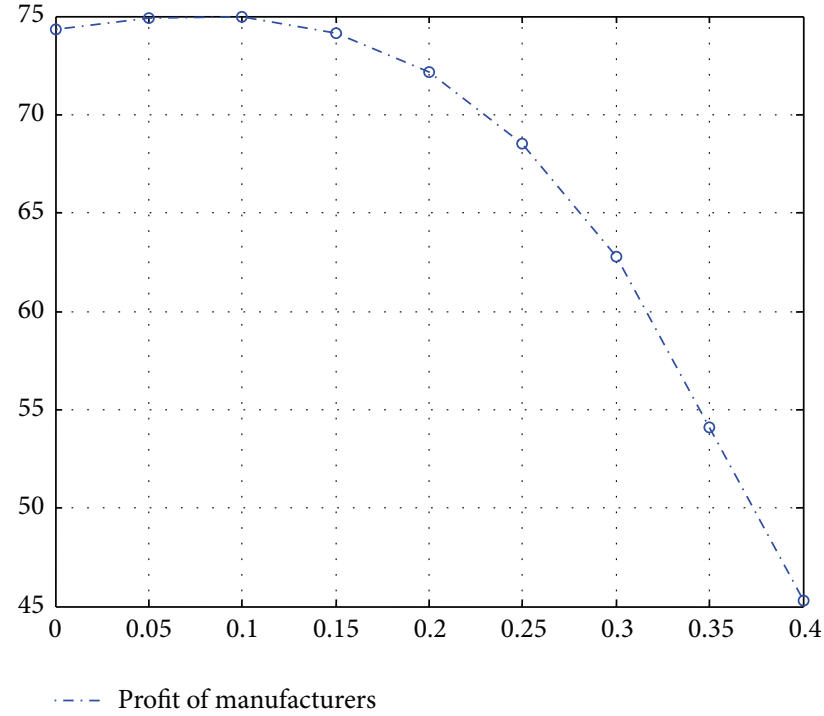

(b) Profit of manufacturers

(a) Profit of suppliers

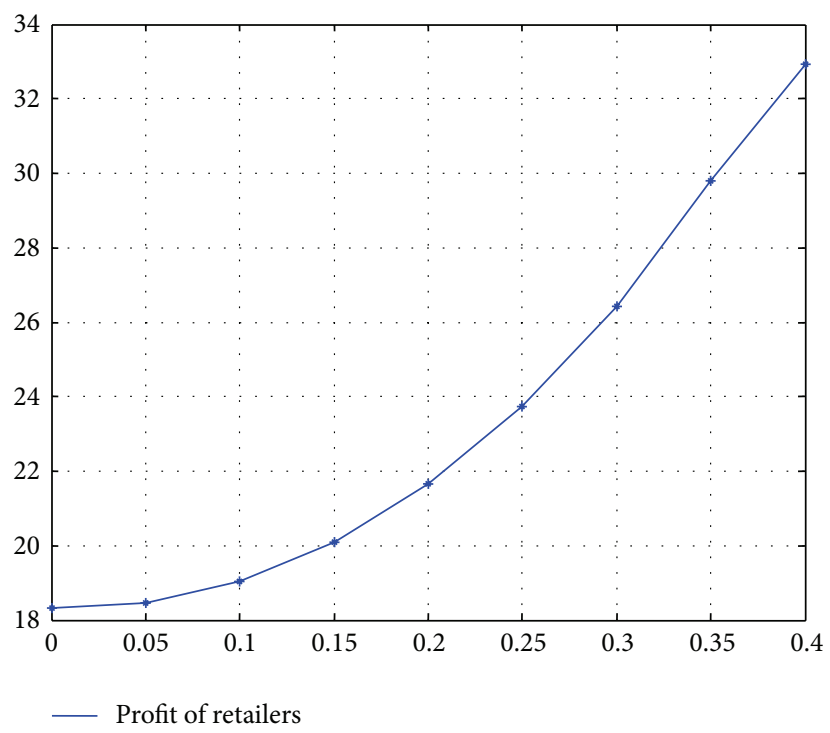

(c) Profit of retailers

FIGURE 2: Profits of various players in CLSC.

become lower, while the amounts of collected products in the previous period are larger with the caps; in other period, the collected used products of the manufacturers are smaller. The profits of all players in the CLSC network decrease as the caps become smaller. With the carbon emission caps appearing in Table 3, the decision-makers consider the whole planning horizon comprehensively to obtain the optimal strategy, but not merely a single period.

\section{Conclusion}

In this paper, we studied the multiperiod CLSC network including manufacturers, retailers, and demand markets taking the product lifetime into account. By using the variational inequalities and complementary theory, we established the CLSC network equilibrium model and solved the model by LQP P-C algorithm. In the end, we provided four numerical examples to illustrate the validity of the modeling framework with or without carbon emission cap, and then we explored the managerial insights in practice. Through the analysis in the numerical examples, we make conclusions as follows.

(1) The increase of product lifetime will enhance the burden of manufacturers and then decrease their profits; the other players in the CLSC are almost not affected; the objects of the manufactures and the whole CLSC are different in general.

(2) The increase of $\alpha$ stimulates the transaction of the network, but it is not always a benefit to the CLSC. 
TABLE 3: $\delta=0$ and $\alpha=0.25$, the CLSC network equilibrium results of various emission caps.

\begin{tabular}{|c|c|c|c|c|c|c|}
\hline$B_{m}(1), m=1,2$ & 3.2 & 3 & 3.2 & 3.2 & 3.2 & 3.2 \\
\hline$B_{m}(2), m=1,2$ & $\infty$ & $\infty$ & 2.3 & 2 & 2.3 & 2.3 \\
\hline$B_{m}(3), m=1,2$ & $\infty$ & $\infty$ & $\infty$ & $\infty$ & 1.8 & 1.6 \\
\hline \multirow{5}{*}{$\begin{array}{l}q_{s}^{r}, q_{m}^{r} \\
s=1,2 ; \\
m=1,2\end{array}$} & 3.2 & 3 & 3.2 & 3.2 & 3.2 & 3.2 \\
\hline & 2.2079 & 2.2218 & 2.1975 & 1.8906 & 2.2025 & 2.2131 \\
\hline & 1.7200 & 1.7298 & 1.7207 & 1.7430 & 1.6221 & 1.4108 \\
\hline & 1.4044 & 1.4121 & 1.4050 & 1.4223 & 1.4108 & 1.4234 \\
\hline & 1.2400 & 1.2463 & 1.2405 & 1.2546 & 1.2452 & 1.2555 \\
\hline \multirow{4}{*}{$\begin{array}{l}q_{m}^{u} \\
m=1,2\end{array}$} & 0.2045 & 0.1952 & 0.2050 & 0.2187 & 0.1951 & 0.1739 \\
\hline & 0.3462 & 0.3390 & 0.3454 & 0.3214 & 0.3559 & 0.3784 \\
\hline & 0.4383 & 0.4306 & 0.4378 & 0.4221 & 0.4282 & 0.4078 \\
\hline & 0.9018 & 0.8947 & 0.9012 & 0.8849 & 0.8967 & 0.8870 \\
\hline \multirow{3}{*}{$\begin{array}{l}s_{m} \\
m=1,2\end{array}$} & 2.0993 & 3.7721 & 2.1126 & 2.5025 & 2.2441 & 2.5256 \\
\hline & 0 & 0 & 0.1436 & 4.3694 & 0.2132 & 0.3622 \\
\hline & 0 & 0 & 0 & 0 & 1.8580 & 5.8363 \\
\hline$\pi_{s}, s=1,2$ & 39.8379 & 38.7104 & 39.7563 & 37.5784 & 38.8658 & 37.1742 \\
\hline$\pi_{n}, n=1,2$ & 70.3260 & 68.5201 & 70.1648 & 65.7157 & 68.0905 & 63.8557 \\
\hline$\pi_{m}, m=1,2$ & 24.3986 & 23.7460 & 24.3539 & 23.0658 & 23.9874 & 23.2293 \\
\hline Total profit & 134.5625 & 130.9765 & 134.2750 & 126.3599 & 130.9437 & 124.2592 \\
\hline
\end{tabular}

The government should set the collection rate in a suitable region based on the manufacturers' collection cost structure and benefits from remanufacturing.

(3) The existence of carbon emission cap will lead to the fact that the profits of all players are lower than those with no carbon emission cap.

(4) When setting carbon emission caps in some periods, the supply amounts of raw materials become lower in these periods, while the amount of collected products is larger in the previous period with the caps; the endogenous carbon tax is larger when the cap of carbon emission is lower.

We hope that the insights and corresponding results obtained in this paper may be useful and helpful in theory and practice and enhance the operating quality of enterprises in CLSC.

\section{Conflict of Interests}

The authors declare that there is no conflict of interests regarding the publication of this paper.

\section{Acknowledgments}

This paper is supported by the National Natural Science Foundation, China (nos. 71202142 and 71371102) and International (Regional) Cooperation and Exchange, China (no. $71311120090)$.

\section{References}

[1] M. A. Seitz and K. Peattie, "Meeting the closed-loop challenge: the case of remanufacturing," California Management Review, vol. 46, no. 2, pp. 74-89, 2004.
[2] R. Giuntini and K. Gaudette, "Remanufacturing: the next great opportunity for boosting US productivity," Business Horizons, vol. 46, no. 6, pp. 41-48, 2003.

[3] A. Atasu, V. D. R. Guide Jr., and L. N. van Wassenhove, "So what if remanufacturing cannibalizes my new product sales?" California Management Review, vol. 52, no. 2, pp. 56-76, 2010.

[4] P. Martin, V. D. R. Guide, and C. W. Craighead, "Supply chain sourcing in remanufacturing operations: an empirical investigation of remake versus buy," Decision Sciences, vol. 41, no. 2, pp. 301-324, 2010.

[5] G. Ferrer and J. M. Swaminathan, "Managing new and differentiated remanufactured products," European Journal of Operational Research, vol. 203, no. 2, pp. 370-379, 2010.

[6] D. Hammond and P. Beullens, "Closed-loop supply chain network equilibrium under legislation," European Journal of Operational Research, vol. 183, no. 2, pp. 895-908, 2007.

[7] J. Sue, "Why buy remanufactured? Recharger Magazine," 2000, http://www.rechargermag.com/.

[8] Kodak, 1998 Corporate Environment Annual Report, The Kodak Corporation, Rochester, NY, USA, 1999.

[9] R. Geyer, L. N. Van Wassenhove, and A. Atasu, "The economics of remanufacturing under limited component durability and finite product life cycles," Management Science, vol. 53, no. 1, pp. 88-100, 2007.

[10] C. Hepburn, "Carbon trading: a review of the kyoto mechanisms," Annual Review of Environment and Resources, vol. 32, pp. 375-393, 2007.

[11] P. Majumder and H. Groenevelt, "Competition in remanufacturing," Production and Operations Management, vol. 10, no. 2, pp. 125-141, 2001.

[12] L. G. Debo, L. B. Toktay, and L. N. Van Wassenhove, "Market segmentation and product technology selection for remanufacturable products," Management Science, vol. 51, no. 8, pp. 11931205, 2005.

[13] M. E. Ferguson and L. B. Toktay, "The effect of competition on recovery strategies," Production and Operations Management, vol. 15, no. 3, pp. 351-368, 2006. 
[14] S. Webster and S. Mitra, "Competitive strategy in remanufacturing and the impact of take-back laws," Journal of Operations Management, vol. 25, no. 6, pp. 1123-1140, 2007.

[15] G. Ferrer and J. M. Swaminathan, "Managing new and remanufactured products," Management Science, vol. 52, no. 1, pp. 1526, 2006.

[16] J.-M. Chen and C.-I. Chang, "Dynamic pricing for new and remanufactured products in a closed-loop supply chain," International Journal of Production Economics, vol. 146, no. 1, pp. 153160, 2013.

[17] Y. Xiong, G. Li, Y. Zhou, K. Fernandes, R. Harrison, and Z. Xiong, "Dynamic pricing models for used products in remanufacturing with lost-sales and uncertain quality," International Journal of Production Economics C, vol. 147, pp. 678-688, 2013.

[18] P. De Giovanni and G. Zaccour, "A two-period game of a closedloop supply chain," European Journal of Operational Research, vol. 232, no. 1, pp. 22-40, 2014.

[19] G.-F. Yang, Z.-P. Wang, and X.-Q. Li, “The optimization of the closed-loop supply chain network," Transportation Research E: Logistics and Transportation Review, vol. 45, no. 1, pp. 16-28, 2009.

[20] Q. Qiang, K. Ke, T. Anderson, and J. Dong, “The closed-loop supply chain network with competition, distribution channel investment, and uncertainties," Omega, vol. 41, no. 2, pp. 186194, 2013.

[21] J. M. Cruz and T. Wakolbinger, "Multiperiod effects of corporate social responsibility on supply chain networks, transaction costs, emissions, and risk," International Journal of Production Economics, vol. 116, no. 1, pp. 61-74, 2008.

[22] Y. Hamdouch, "Multi-period supply chain network equilibrium with capacity constraints and purchasing strategies," Transportation Research C: Emerging Technologies, vol. 19, no. 5, pp. 803-820, 2011.

[23] J. M. Cruz and Z. Liu, "Modeling and analysis of the multiperiod effects of social relationship on supply chain networks," European Journal of Operational Research, vol. 214, no. 1, pp. 39-52, 2011.

[24] X. Gong and S. X. Zhou, "Optimal production planning with emissions trading," Operations Research, vol. 61, no. 4, pp. 908924, 2013.

[25] K. Wu, A. Nagurney, Z. Liu, and J. K. Stranlund, "Modeling generator power plant portfolios and pollution taxes in electric power supply chain networks: a transportation network equilibrium transformation," Transportation Research D: Transport and Environment, vol. 11, no. 3, pp. 171-190, 2006.

[26] A. Nagurney, Z. Liu, and T. Woolley, "Optimal endogenous carbon taxes for electric power supply chains with power plants," Mathematical and Computer Modelling, vol. 44, no. 910, pp. 899-916, 2006.

[27] H. Krikke, "Impact of closed-loop network configurations on carbon footprints: a case study in copiers," Resources, Conservation and Recycling, vol. 55, no. 12, pp. 1196-1205, 2011.

[28] D. Kannan, A. Diabat, M. Alrefaei, K. Govindan, and G. Yong, "A carbon footprint based reverse logistics network design model," Resources, Conservation and Recycling, vol. 67, pp. 7579, 2012.

[29] R. C. Savaskan, S. Bhattacharya, and L. N. Van Wassenhove, "Closed-loop supply chain models with product remanufacturing," Management Science, vol. 50, no. 2, pp. 239-252, 2004.

[30] T. Clottey and W. C. Benton, "Determining core acquisition quantities when products have long return lags," IIE Transactions, 2014.
[31] G. M. Korpelevich, "The extra gradient method for finding saddle points and other problems," Matekon, vol. 13, pp. 35-49, 1977.

[32] B.-S. He, Y. Xu, and X.-M. Yuan, "A logarithmic-quadratic proximal prediction-correction method for structured monotone variational inequalities," Computational Optimization and Applications, vol. 35, no. 1, pp. 19-46, 2006. 


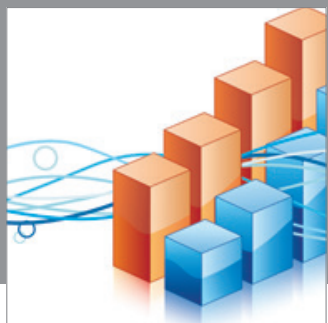

Advances in

Operations Research

mansans



The Scientific World Journal
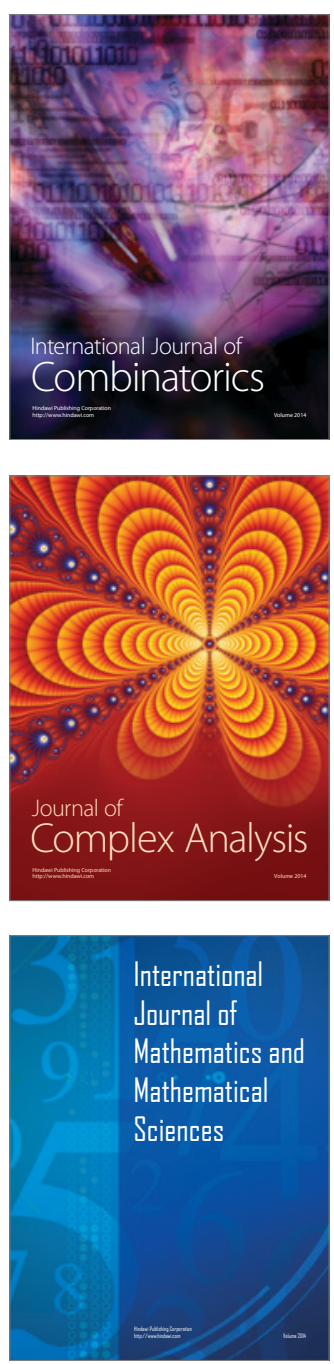
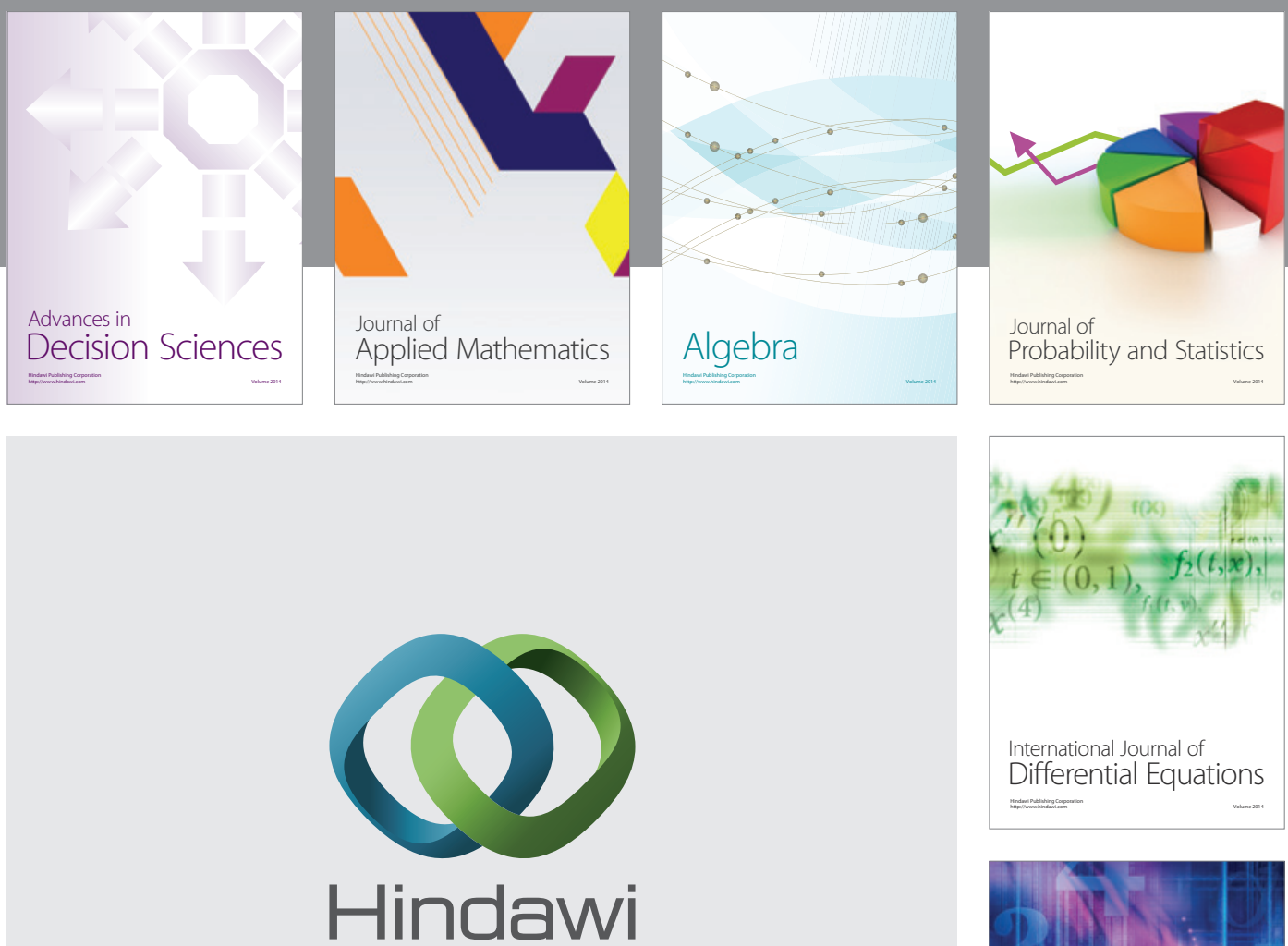

Submit your manuscripts at http://www.hindawi.com
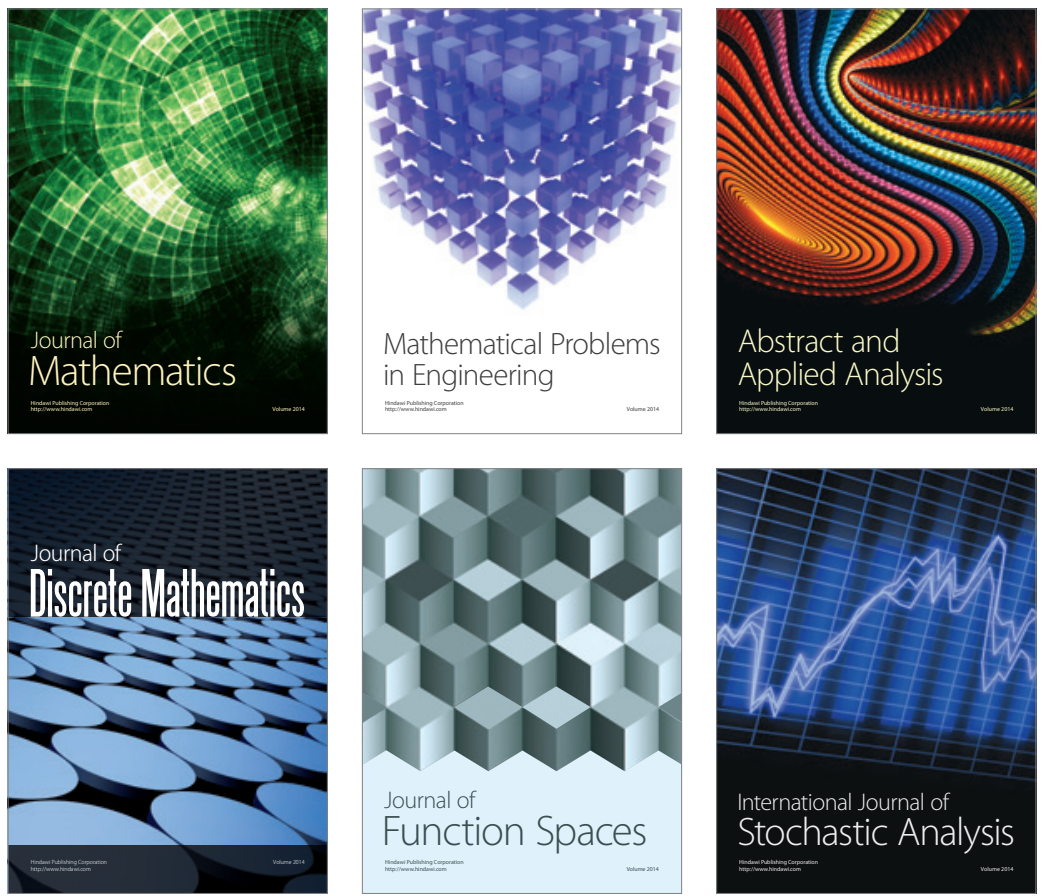

Journal of

Function Spaces

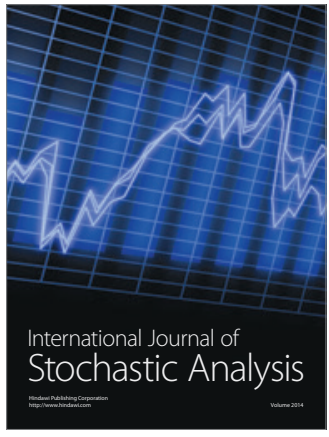

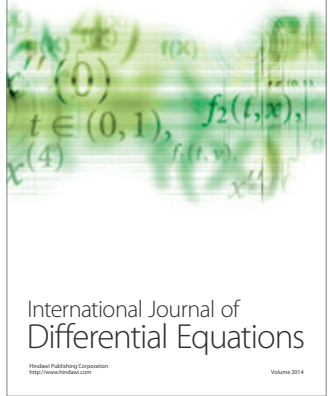
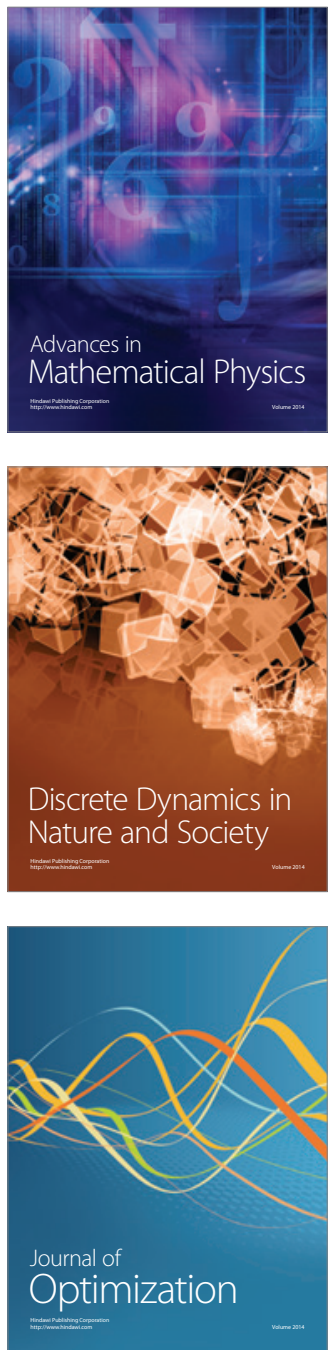